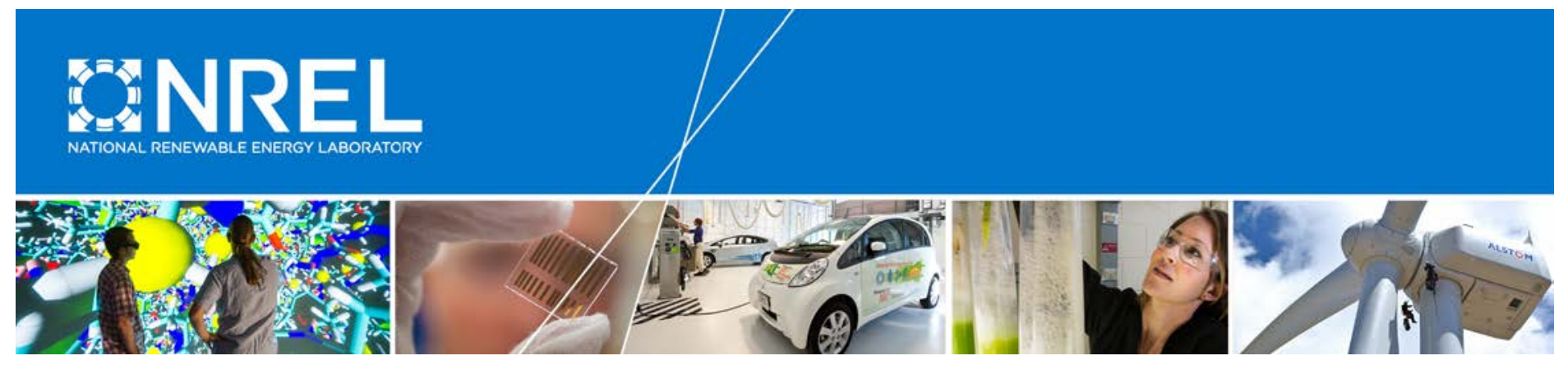

\title{
Deployment of Wind Turbines in the Built Environment: Risks, Lessons, and Recommended Practices
}

Jason Fields, Frank Oteri, Robert Preus, and lan Baring-Gould National Renewable Energy Laboratory

NREL is a national laboratory of the U.S. Department of Energy Office of Energy Efficiency \& Renewable Energy Operated by the Alliance for Sustainable Energy, LLC

This report is available at no cost from the National Renewable Energy Laboratory (NREL) at www.nrel.gov/publications.

Technical Report

NREL/TP-5000-65622

June 2016 


\section{Deployment of Wind Turbines in the Built Environment: \\ Risks, Lessons, and Recommended Practices}

Jason Fields, Frank Oteri, Robert Preus, and lan Baring-Gould

National Renewable Energy Laboratory

Prepared under Task No. WE152e22

NREL is a national laboratory of the U.S. Department of Energy Office of Energy Efficiency \& Renewable Energy Operated by the Alliance for Sustainable Energy, LLC

This report is available at no cost from the National Renewable Energy Laboratory (NREL) at www.nrel.gov/publications.

National Renewable Energy Laboratory 15013 Denver West Parkway Golden, CO 80401

303-275-3000 • www.nrel.gov

\section{Technical Report}

NREL/TP-5000-65622

June 2016

Contract No. DE-AC36-08G028308 


\title{
NOTICE
}

This report was prepared as an account of work sponsored by an agency of the United States government. Neither the United States government nor any agency thereof, nor any of their employees, makes any warranty, express or implied, or assumes any legal liability or responsibility for the accuracy, completeness, or usefulness of any information, apparatus, product, or process disclosed, or represents that its use would not infringe privately owned rights. Reference herein to any specific commercial product, process, or service by trade name, trademark, manufacturer, or otherwise does not necessarily constitute or imply its endorsement, recommendation, or favoring by the United States government or any agency thereof. The views and opinions of authors expressed herein do not necessarily state or reflect those of the United States government or any agency thereof.

This report is available at no cost from the National Renewable Energy Laboratory (NREL) at www.nrel.gov/publications.

Available electronically at SciTech Connect http:/www.osti.gov/scitech

Available for a processing fee to U.S. Department of Energy and its contractors, in paper, from:

\author{
U.S. Department of Energy \\ Office of Scientific and Technical Information \\ P.O. Box 62 \\ Oak Ridge, TN 37831-0062 \\ OSTI http://www.osti.gov \\ Phone: 865.576.8401 \\ Fax: 865.576.5728 \\ Email: reports@osti.gov
}

Available for sale to the public, in paper, from:

\author{
U.S. Department of Commerce \\ National Technical Information Service \\ 5301 Shawnee Road \\ Alexandria, VA 22312 \\ NTIS http://www.ntis.gov \\ Phone: 800.553 .6847 or 703.605 .6000 \\ Fax: 703.605.6900 \\ Email: orders@ntis.gov
}




\section{Acknowledgments}

The National Renewable Energy Laboratory (NREL) acknowledges the U.S. Department of Energy's Wind and Water Power Technologies Office for supporting this work under the Office of Energy Efficiency and Renewable Energy's distributed wind research, development, and testing activities. We would especially like to thank the following associates who contributed to the case studies:

- Mike Ewert and Jeff White, National Air and Space Administration (NASA) Johnson Space Center

- Renee Loveland, Gerding Edlen (Twelve West)

- Josue Sanchez, L\&M Development Partners (Pearson Court Square)

- Marian Tomusiak, Boston Museum of Science Wind Turbine Lab

- Elliot Matz and John Coburn, Brooklyn Navy Yard

- Bryan Wagoner and James Power, Wayne County Airport Authority (Detroit Metro Airport).

NREL would also like to thank Mike van Bavel and Bobby Ghuneim from Dynamax Inc. They were a great help in executing the NASA Building 12 measurement program. 


\section{List of Abbreviations and Acronyms}

BEWT

CFD

HAWT

IEA

IEC

$\mathrm{kW}$

$\mathrm{kWh}$

LCOE

LEED

LES

NASA

NREL

NTM

TFPZ

TI

VAWT built-environment wind turbine

computational fluid dynamics

horizontal-axis wind turbine

International Energy Agency

International Electro-technical Committee

kilowatt

kilowatt-hours

levelized cost of energy

Leadership in Energy \& Environmental Design

large eddy simulation

National Air and Space Administration

National Renewable Energy Laboratory

Normal Turbulence Model

turbine failure projectile zone

turbulence intensity

vertical-axis wind turbine 


\section{Executive Summary}

Built-environment wind turbine (BEWT) projects are wind energy projects that are constructed on, in, or near buildings. These projects present an opportunity for distributed, low-carbon generation combined with highly visible statements on sustainability, but the BEWT niche of the wind industry is still developing and is relatively less mature than the utility-scale wind or conventional ground-based distributed wind sectors. The findings from this report cannot be extended to wind energy deployments in general because of the large difference in application and technology maturity.

This paper investigates the current state of the BEWT industry by reviewing available literature on BEWT projects as well as interviewing project owners on their experiences deploying and operating the technology. The authors generated a series of case studies that outlines the pertinent project details, project outcomes, and lessons learned. This paper integrates those information sources into recommended practices that can be utilized by future stakeholders to evaluate the feasibility of BEWTs for their unique applications and sites. It should be noted that due to the lack of available information, the case studies were limited to building-mounted designs with limited coverage of building-integrated turbines (in which the architectural structure is shaped to support wind generation). The recommended practices are still largely applicable to any built-environment technology or approach.

Lessons learned from the case studies include the following:

- Project planning

- Project feasibility and planning processes are insufficient and not well defined. A few project developers undertook rigorous pre-construction planning, and those projects tended to have more positive outcomes.

- Project costs

- Additional expenses related to installation and operations in the built environment can create high-cost projects.

- Project performance and reliability

- Consolidation of small turbine manufacturers has been common and can lead to loss of warranty and difficulty in service parts availability.

- BEWT project performance is often over-estimated when compared with actual production. None of the case study projects met their energy production estimates, largely due to the complexity of conducting accurate resource and production assessments in complex built environments. Onsite atmospheric measurements are recommended, along with detailed loss calculations to account for real-world operating conditions.

In general, the BEWT industry has experienced mixed results, with some positive project outcomes and several negative outcomes for stakeholders. We see that projects with positive outcomes usually share the following commonalities: 
- Project goals have been well developed and quantified. These goals typically include some education or marketing component and do not rely solely on energy production.

- BEWT project developers conducted rigorous due diligence and devoted time to planning before deployment.

- BEWT projects are placed on taller buildings relative to surrounding obstacles (Encraft 2009).

- Project developers selected certified horizontal axis wind turbines (HAWTs) with a strong track record of previous deployments.

It should also be noted that based on several key factors (i.e., wind speeds are typically lower and costs for implementing projects in built environments are typically higher), projects in the built environment can be difficult to justify on a cost of energy or energy offset basis. Understanding the expected production of a wind turbine in the built environment is a very complex undertaking; the use of onsite resource measurements combined with high-fidelity models is likely the only way to understand the expected turbine production.

While the BEWT industry is evolving, it appears that these projects are still an emerging wind energy application. Stakeholders considering a BEWT project should review the case study outcomes, lessons learned, and recommended practices to help inform their decision processes. 


\section{Table of Contents}

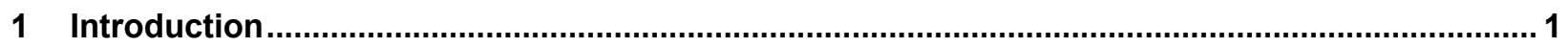

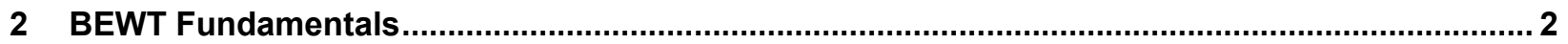

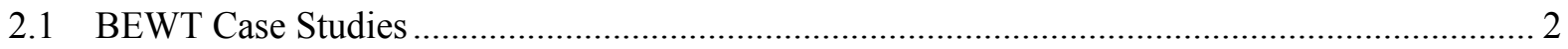

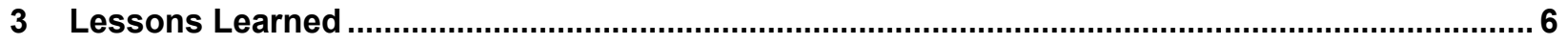

3.1 Project Planning Lessons Learned ……………………………………………………... 7

3.1.1 Project feasibility and planning processes are insufficient and not well defined............. 7

3.1.2 Multi-objective projects tend to be perceived as more successful................................. 8

3.1.3 The order in which objectives are prioritized can influence project outcomes................ 9

3.1.4 Potential liability and safety issues should be understood and addressed during the planning process .............................................................................................

3.1.5 Concerns regarding a project's impact on local aviation procedures can add unanticipated steps to the permitting process................................................................... 9

3.2 Project Costs Lessons Learned......................................................................................... 10

3.2.1 Additional expenses related to installation in the built environment can create high-cost

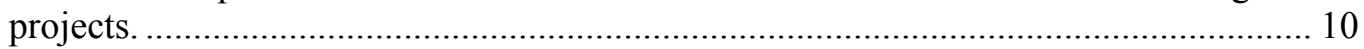

3.2.2 The potential additional complexities of performing maintenance on BEWTs can lead to cumbersome and expensive practices. .................................................................... 10

3.3 Project Performance and Reliability Lessons Learned............................................................. 11

3.3.1 Consolidation of small turbine manufacturers has been common and can lead to loss of warranty and difficulty in service parts availability................................................... 11

3.3.2 BEWT project performance is often over-estimated when compared with actual production. ........................................................................................................ 11

3.3.3 Current national and international standards do not reflect wind conditions often seen in the built environment. ……………………………………………………………...... 12

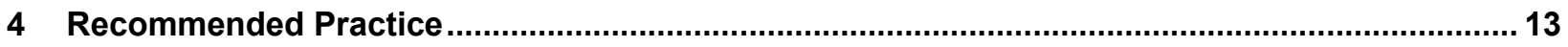

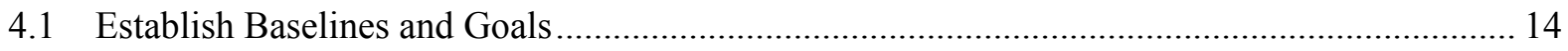

4.2 Perform a Technical Evaluation ................................................................................... 14

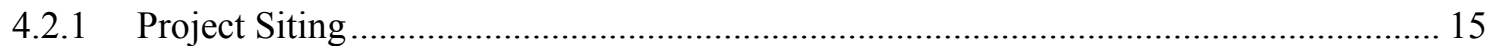

4.2.2 Comfort and Safety of Building Occupants, Equipment Safety, and Liability .............. 15

4.2.3 Wind Resource ................................................................................................. 16

4.2.4 Turbine Certification and Selection …………………………………………... 22

4.2.5 Energy Production................................................................................................ 23

4.3 Estimate Project Costs and Conduct a Cost-Benefit Analysis …………....................................2 24

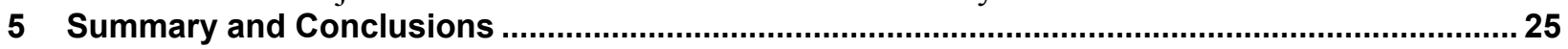

5.1 Case Studies and Lessons Learned........................................................................................2

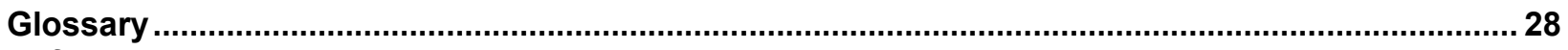

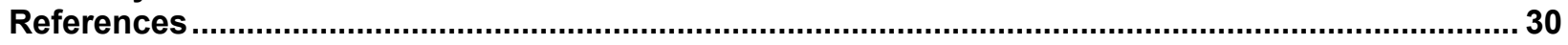

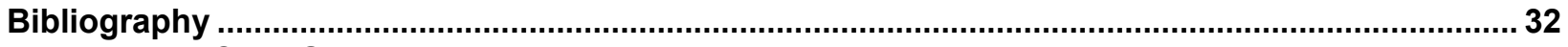

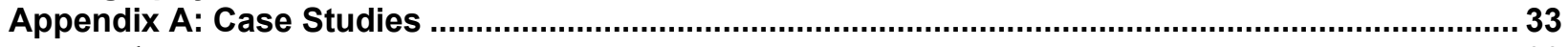

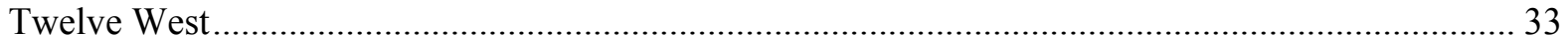

Detroit Metro Airport …………………………………………………………………….... 35

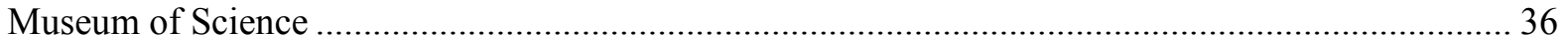

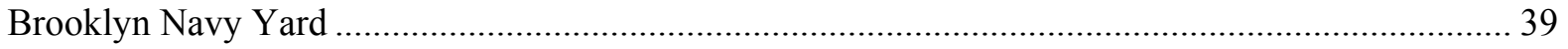

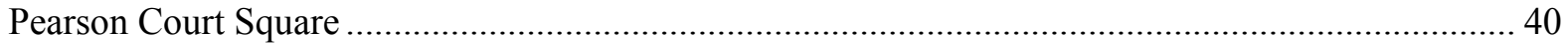

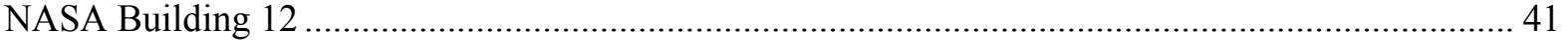




\section{List of Figures}

Figure 1. Illustration of turbine installations in the built environment .................................................. 1

Figure 2. Conventional open-flow field environment. Photo from Gwen Bassetti, NREL 26429 .............. 2

Figure 3. Example of a built environment installation on Boston City Hall. Photo by Joe Smith, NREL 18462

Figure 4. LES simulation of wind flow around building (Toja Silva 2015)....

Figure 5. NASA Building 12 frequency distribution of the wind speeds at the four planned turbine locations and power curve for the UGE turbines that were installed.

Figure 6. Turbulence intensity and wind distribution, $2 \mathrm{~m}$ above rooftop in Melville, Western Australia, during January-February 2009 (Whale 2012)

Figure 7. Standard deviation of stream-wise wind velocity based on building orientation and the ratio of building height (z) versus breadth (b) (Kono and Kogaki 2012) ...................................... 22

Figure 8. Twelve West wind turbine installation in Portland, OR. Photo from Flickr 4852149002 .......... 33

Figure 9. Detroit Metro Airport Windspire installation. Photo from Wayne County Airport Authority..... 35

Figure 10. Skystream installation at the Boston Museum of Science. Photo from Boston Museum of Science, NREL 18006

Figure 11. Brooklyn Navy Yard wind turbine installation. Photo from Flickr 2874788682 .................... 39

Figure 12. NASA Building 12 wind turbine installations. Photo by Dave Jager, NREL ....................... 42

Figure 13. A part of the NASA Building 12 project assessment, this elevation map shows the height of

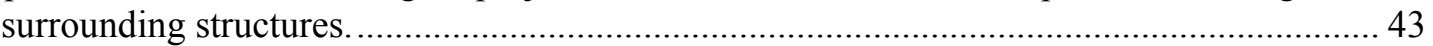

Figure 14. Aerial satellite photo showing the layout of the NASA Building 12 project ......................... 43

Figure 15. NASA Building 12 monthly average wind speeds ........................................................... 44

Figure 16. Monitoring data from the NASA Building 12 for March 2015 including wind direction (WD), wind speed (WS), expected power (UGE PWR), and actual power in watts for the four installed turbines.

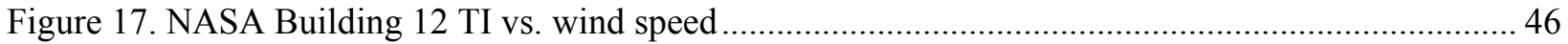

\section{List of Tables}

Table 1. Turbine Models Used in U.S. Built-Environment Installations ................................................... 4

Table 2. Overview of BEWT Project Case Studies ................................................................................ 5

Table 3. Summary of IEC 61400-2 Wind Characteristics that Differ between Built-Environment and

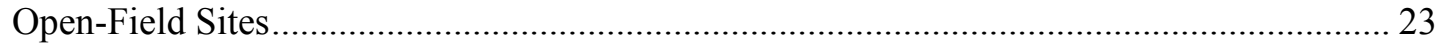

Table 4. NASA Building 12 Predicted vs Actual Energy (March 2015) ................................................. 45 


\section{Introduction}

Built-environment wind turbines (BEWTs) are wind turbines located in an urban or suburban environment (built environment). BEWTs may be mounted on buildings or among buildings, as shown in Figure 1. They can also be integrated into a building and included in the building design from architectural, structural, and economic perspectives. A BEWT attached to a building may be an attractive prospect for a project developer because it offers an opportunity for locally produced energy similar to a solar photovoltaic system. However, unlike solar photovoltaic systems, BEWT systems have additional challenges that should be considered.

The purpose of this document is to summarize the current state of BEWT deployment as well as provide practical recommendations for entities considering a BEWT project. This document examines the challenges and risks inherent to BEWT design and installation and provides guidelines for addressing those challenges. We review the best available information on the complexities of wind resource assessment in the built environment, along with the challenges of structural integration, among others. These complexities will be demonstrated through a number of real-world case studies so the reader can more clearly understand the opportunities and challenges associated with BEWT projects.

The typical motivation for the installation of a standard open-field distributed wind turbine is often primarily energy production leading to an overall reduction of energy costs. However, BEWT projects may pose challenging economics on the basis of energy production alone. In addition to the value of the energy generated, some of the other possible benefits are:

- Leadership in Energy \& Environmental Design (LEED) certification credits

- Marketing or public relations value for a commercial building

- Meeting carbon reduction targets or renewable energy targets ${ }^{1}$

- Supporting local and/or onsite generation

- Utilization of federal, state, and utility incentives

- Education and outreach.

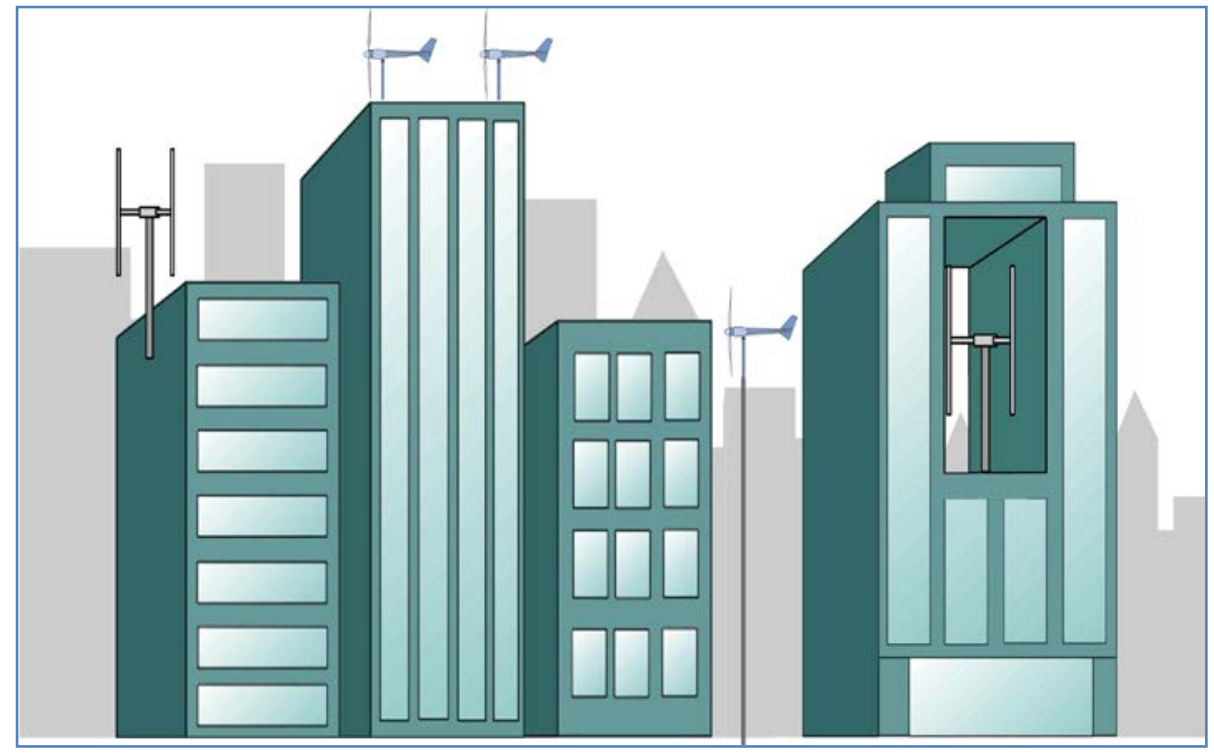

Figure 1. Illustration of turbine installations in the built environment

\footnotetext{
${ }^{1}$ BEWT projects may not be optimal for obtaining carbon reduction or renewable energy targets as those are usually tied to energy production.
} 


\section{BEWT Fundamentals}

BEWTs refer to a market niche, not a particular size or category. As shown in Figure 1, BEWTs can be mounted on the side of a building, integrated into buildings, or ground mounted among buildings in an urban environment. Most BEWTs are small wind turbines that are $\sim 10$ kilowatts $(\mathrm{kW})$ nameplate or less. Table 1 lists the wind turbines deployed in the built environment in the United States and provides a representation of the turbine diversity. In general, BEWTs are conventional wind turbine designs installed in the built environment. A few BEWT-specific offerings have appeared in the market, but they are generally short-lived and without a strong market history. Most of the BEWT-specific offerings appeared around 2009 at the height of the distributed wind boom. Even though most BEWTs use conventional designs, many of those conventional turbines were designed for an open-flow field environment, not a built environment. Figure 2 shows an example of an open-flow field environment.

\subsection{BEWT Case Studies}

National Renewable Energy Laboratory (NREL) researchers generated a series of practical case studies with a goal of creating an informative product that accurately portrays the experiences of current builtenvironment wind projects from concept through installation. The case studies were selected based on the availability of public information on the projects and the identification of project representatives who could be interviewed. With the exception of the National Air and Space Administration (NASA) Building 12 installation, NREL researchers did not directly measure any project data; all pre- and postconstruction energy estimates were provided by project owners. Table 2 provides a summary of these projects, which are introduced in the next section. Full details on each can be found in Appendix A. While the installations encountered significant performance variations compared to estimated generation, some did provide positive benefits beyond energy production. These six BEWT sites from project developers who participated in this study represent seven small wind turbine models and 32 wind turbines. Notably absent from these case studies are building-integrated turbines; none are known to be installed in the United States at this time.

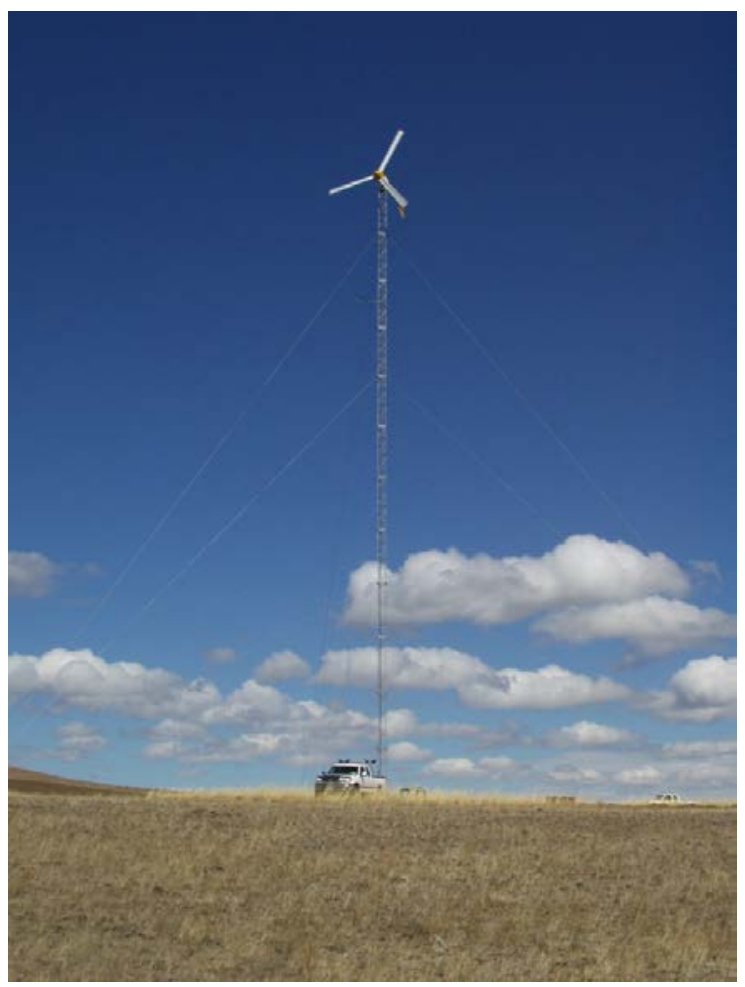

Figure 2. Conventional open-flow field environment. Photo from Gwen Bassetti, NREL 26429 


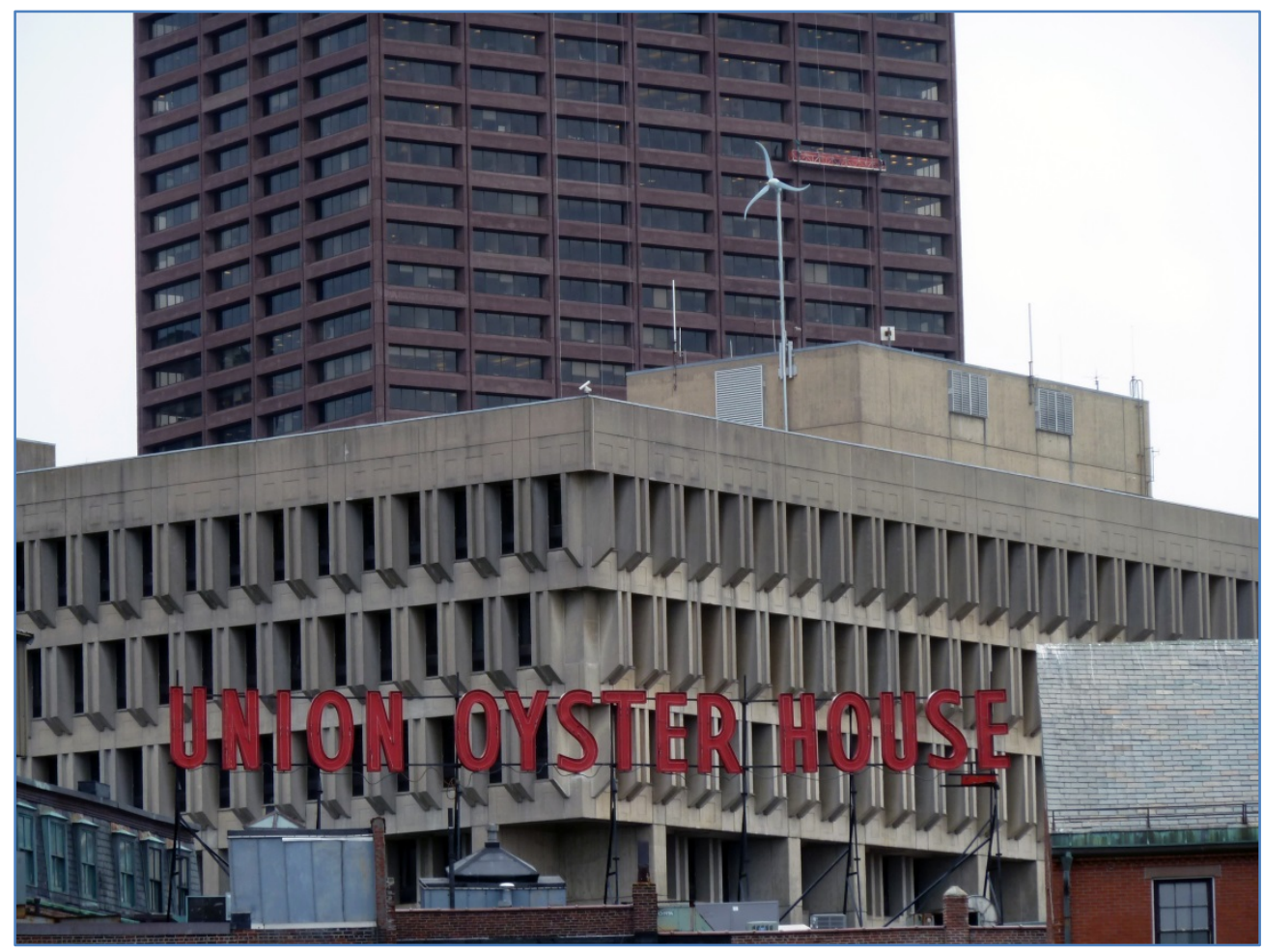

Figure 3. Example of a built environment installation on Boston City Hall. Photo by Joe Smith, NREL 18462

Of the six projects that are profiled, the NASA Building 12 project is unique among the case studies as it involved detailed pre-construction and post-construction measurements. NREL researchers initiated a measurement campaign consisting of multiple rooftop anemometers and other atmospheric instrumentation located on the prospective turbine pad mounts and in the immediate rooftop vicinity. The Building 12 measurement program consisted of two phases: Phase $1^{2}$ is the pre-construction measurement campaign, and Phase 2 is the post-construction measurement campaign. The full installation and commissioning documentation and datasets are also available. ${ }^{3}$ The power data for Phase 2 were measured by the NASA enterprise Supervisory Control and Data Acquisition system and contain inputs directly from the turbine inverters. As of the writing of this document, Phase 2 data collection is ongoing, so this report contains a subset of the total data.

\footnotetext{
${ }^{2}$ Phase 1 data are available at http://en.openei.org/doe-opendata/dataset/nasa-building-12-wind-turbines-phase-1-data

${ }^{3} \mathrm{http}$ ://en.openei.org/wiki/NASA_Building_12 Wind_Turbines 
Table 1. Turbine Models Used in U.S. Built-Environment Installations

\begin{tabular}{|c|c|c|c|c|}
\hline Turbine Manufacturer & Turbine Model & $\begin{array}{l}\text { Turbine } \\
\text { Orientation }\end{array}$ & $\begin{array}{l}\text { Turbine } \\
\text { Capacity }\end{array}$ & $\begin{array}{l}\text { Currently } \\
\text { Active? }\end{array}$ \\
\hline Aerotecture & $\begin{array}{l}610 \mathrm{~V} \\
\text { Aeroturbine }\end{array}$ & VAWT* $^{*}$ & $1 \mathrm{~kW}$ & Defunct \\
\hline Aerotecture & $\frac{712 \mathrm{~V}}{\text { Aeroturbine }}$ & VAWT & $2.5 \mathrm{~kW}$ & Defunct \\
\hline AeroVironment & $\underline{\text { AVX1000 }}$ & HAWT** & $1 \mathrm{~kW}$ & $\begin{array}{l}\text { Active but } \\
\text { exited wind } \\
\text { energy }\end{array}$ \\
\hline Bergey & Bergey Excel & HAWT & $10 \mathrm{~kW}$ & Active \\
\hline Britwind (formerly Evance) & $\underline{\mathrm{R} 9000}$ & HAWT & $5 \mathrm{~kW}$ & $\begin{array}{l}\text { Active } \\
\text { (Re-structured) }\end{array}$ \\
\hline Cascade & $\underline{\text { Swift }}$ & HAWT & $1 \mathrm{~kW}$ & $\begin{array}{l}\text { Active but } \\
\text { exited wind } \\
\text { energy }\end{array}$ \\
\hline Gaia Wind & $\underline{\text { Gaia Wind } 133}$ & HAWT & $11 \mathrm{~kW}$ & Active \\
\hline Helix Wind & Eolico 5 KW & VAWT & $5 \mathrm{~kW}$ & Defunct \\
\hline Home Energy & $\begin{array}{l}\text { EnergyBall } \\
\underline{\text { V200 }}\end{array}$ & HAWT & $2.5 \mathrm{~kW}$ & Defunct \\
\hline Honeywell & Windtronics & HAWT & $2 \mathrm{~kW}$ & $\begin{array}{l}\text { Active but } \\
\text { exited wind } \\
\text { energy }\end{array}$ \\
\hline JLM Energy & $\underline{\text { Zefr }}$ & HAWT & $240 \mathrm{~W}$ & Defunct \\
\hline $\begin{array}{l}\text { Kingspan (formerly Proven } \\
\text { Energy) }\end{array}$ & $\begin{array}{l}\text { KW6 } \\
\text { (Proven 6) }\end{array}$ & HAWT & $6 \mathrm{~kW}$ & $\begin{array}{l}\text { Active } \\
\text { (Re-structured) }\end{array}$ \\
\hline $\begin{array}{l}\text { Primus WindPower } \\
\text { (formerly Southwest } \\
\text { Windpower) }\end{array}$ & Air X & HAWT & $400 \mathrm{~W}$ & $\begin{array}{l}\text { Active } \\
\text { (Re-structured) }\end{array}$ \\
\hline Tangarie & GALE & VAWT & $5 \mathrm{~kW}$ & Defunct \\
\hline Urban Green Energy & Eddy GT & VAWT & $1 \mathrm{~kW}$ & Active \\
\hline Urban Green Energy & $\underline{\text { VisionAIR5 }}$ & VAWT & $3.2 \mathrm{~kW}$ & Active \\
\hline Venger & V1 & HAWT & $2 \mathrm{~kW}$ & Defunct \\
\hline $\begin{array}{l}\text { Windspire Energy (formerly } \\
\text { Mariah Power) }\end{array}$ & Windspire & VAWT & $1.2 \mathrm{~kW}$ & $\begin{array}{l}\text { Active } \\
\text { (Re-structured) }\end{array}$ \\
\hline Wing Power Energy & Unknown & VAWT & $2 \mathrm{~kW}$ & Unknown \\
\hline
\end{tabular}




\begin{tabular}{lllll}
\hline Turbine Manufacturer & Turbine Model & $\begin{array}{l}\text { Turbine } \\
\text { Orientation }\end{array}$ & $\begin{array}{l}\text { Turbine } \\
\text { Capacity }\end{array}$ & $\begin{array}{l}\text { Currently } \\
\text { Active? }\end{array}$ \\
$\begin{array}{lllll}\text { Xzeres (formerly Southwest } \\
\text { Windpower }\end{array}$ & $\underline{\text { Skystream } 3.7}$ & HAWT & $2.4 \mathrm{~kW}$ & $\begin{array}{l}\text { Active } \\
\text { (Re-structured) }\end{array}$ \\
Zephyr & $\underline{\text { AirDolphin }}$ & HAWT & $1.1 \mathrm{~kW}$ & Active \\
& $\underline{\underline{Z 1000}}$ & & & \\
\hline
\end{tabular}

*VAWT: vertical-axis wind turbine

${ }^{* *}$ HAWT: horizontal-axis wind turbine

Table 2. Overview of BEWT Project Case Studies

\begin{tabular}{|c|c|c|c|c|c|c|}
\hline $\begin{array}{l}\text { Project } \\
\text { Name }\end{array}$ & $\begin{array}{l}\text { Twelve } \\
\text { West }\end{array}$ & $\begin{array}{l}\text { Detroit Metro } \\
\text { Airport }\end{array}$ & $\begin{array}{l}\text { Museum of } \\
\text { Science }\end{array}$ & $\begin{array}{l}\text { Brooklyn } \\
\text { Navy Yard }\end{array}$ & $\begin{array}{l}\text { Pearson } \\
\text { Court } \\
\text { Square }\end{array}$ & $\begin{array}{l}\text { NASA } \\
\text { Building } 12\end{array}$ \\
\hline Location & $\begin{array}{l}\text { Portland, } \\
\text { OR }\end{array}$ & Romulus, MI & Boston, MA & Brooklyn, NY & $\begin{array}{l}\text { Long Island } \\
\text { City, NY }\end{array}$ & Houston, TX \\
\hline $\begin{array}{l}\text { Turbine } \\
\text { Type }\end{array}$ & $\begin{array}{l}\text { Skystream } \\
3.7 \text { (4) }\end{array}$ & Windspire (6) & $\begin{array}{l}\text { Windspire (1) } \\
\text { Skystream } \\
3.7(1) \\
\text { Swift (1) } \\
\text { Proven } 6 \text { (1) } \\
\text { AeroVironment } \\
\text { AVX1000 (5) }\end{array}$ & $\begin{array}{l}\text { AeroVironment } \\
\text { AVX } 1000 \text { (6) }\end{array}$ & $\begin{array}{l}\text { VisionAIR5 } \\
\text { (3) }\end{array}$ & Eddy GT (4) \\
\hline Capacity & $9.6 \mathrm{~kW}$ & $7.2 \mathrm{~kW}$ & $15.6 \mathrm{~kW}$ & $6 \mathrm{~kW}$ & $9.6 \mathrm{~kW}$ & $4 \mathrm{~kW}$ \\
\hline $\begin{array}{l}\text { Year } \\
\text { Installed }\end{array}$ & 2009 & 2010 & 2009 & 2008 & 2014 & 2014 \\
\hline Operational & Operating & $\begin{array}{l}\text { Operating at } \\
\text { reduced } \\
\text { capacity }\end{array}$ & $\begin{array}{l}\text { Operating at } \\
\text { reduced } \\
\text { capacity }\end{array}$ & Not operating & Operating & Operating \\
\hline $\begin{array}{l}\text { Roof } \\
\text { Mounted? }\end{array}$ & Yes & No & Yes & Yes & Yes & Yes \\
\hline Owner View & Success & Underperform & Success & Underperform & Success & Underperform \\
\hline
\end{tabular}




\section{Lessons Learned}

Several unique considerations for BEWT projects were revealed during the literature review and the development of the aforementioned case studies. These lessons learned can provide insight for the next generation of built-environment wind projects, potentially leading to a higher level of successful deployments of this technology. Insights include:

- $\quad$ Project planning

○ Project feasibility and planning processes are insufficient and not well defined.

○ Multi-objective projects tend to be perceived as more successful.

○ The order in which objectives are prioritized can and should influence project outcomes.

○ Potential liability and safety issues should be understood and addressed during the planning process.

- Concerns regarding a project's impact on local aviation procedures can add unanticipated steps to the permitting process.

- Project costs

- Additional expenses related to installation in the built environment can create high-cost projects.

- The potential additional complexities of performing maintenance on BEWTs can lead to cumbersome and expensive practices. Additionally, increased turbulence levels common in builtenvironment areas may result in additional maintenance requirements and decreased turbine reliability.

- Project performance and reliability

- Consolidation of small turbine manufacturers has been common and can lead to loss of warranty and difficulty in service parts availability.

- BEWT project performance is often over-estimated when compared with actual production. Onsite atmospheric measurements are recommended along with detailed loss calculations to account for real-world operating conditions if accurate production estimates are desired.

- Although certified turbines should be selected for all small and distributed wind projects, current national and international turbine standards do not reflect wind conditions often seen in the built environment.

Each of these insights is described in greater detail in the following sections. 


\subsection{Project Planning Lessons Learned}

\subsubsection{Project feasibility and planning processes are insufficient and not well defined.}

The project feasibility and planning process is hampered by few BEWT installations and a lack of experienced project developers. Limited public information is available on existing BEWT projects, making it difficult for potential developers to understand challenges. The lack of representative projects also means that there are few experienced installers, even in a given region. The development process also has unique architectural and engineering requirements not typically needed in more conventional turbine installations, again further limiting the experience base. Most projects seem to have been completed by teams with no previous built-environment wind project experience. The built-environment wind resource is complex, leading to estimated production that tends to be higher than actual production.

The complex nature of the built environment increases the necessity of thoroughly understanding a location's wind resource and the influence that surrounding structures and vegetation may have on it. In terms of positive resource and location understanding, one project stands out from the rest. Project developers for the Twelve West installation ${ }^{4}$ conducted an in-depth modeling study with Oregon State University's Aero Engineering Lab to understand the project's wind resource and the influence from surrounding structures. Project developers believe this was essential to their installation's success. The data from this effort helped developers choose an installation location that would allow the project to maximize production while still being located in a highly visible area of the building.

On the opposite end of the spectrum, NASA Building 12 project developers had already committed to their project by purchasing turbines prior to assessing the site's wind resource. This led to the installation of turbines in a location with a low wind resource, which has contributed to the project's lack of generation.

There is a body of research on the behavior of wind around a building. In the sections that follow, we will draw on that research to outline an organized process for assessing a BEWT project. We will also discuss risk of inaccuracy in applying available turbine performance information to a BEWT project.

\footnotetext{
${ }^{4}$ See sidebar for an overview of each case study and Appendix A for detailed information on the projects discussed here.
} 


\subsubsection{Multi-objective projects tend to be perceived as more successful.}

A majority of the project developers who participated in these case studies felt that their installations' success was attributed to the multi-objective approach they established for their developments. In addition to onsite generation, the Twelve West installation moved forward with the goals of installing a project that was capable of raising awareness about renewable energy while elevating the visibility of the building and underscoring the building's sustainability commitment. Project developers feel that the installation continues to meet these objectives and that the overall success of the project can be directly attributed to their multi-objective approach.

Project developers at the Boston Museum of Science adjusted their project goals from generation to education after realizing early in the process that the site did not have the resource necessary to be considered successful from a generation perspective. Primary objectives for the project became:

- Creating a roof-top location where a variety of commercially available small wind turbines could be tested in the built environment

- Providing data and experience for the general public and industry professionals

- Constructing an exhibit that would become a landmark for Boston and the region

- Generating clean energy while making a statement on its importance.

In the case of Pearson Court Square, the project was initiated with three goals in mind: furthering the building's sustainable practices, garnering attention and publicity, and generating energy onsite. While it is still too early in the process to determine the installation's energy generation, the other project objectives have been met. In terms of attention and publicity, the project was highlighted in numerous domestic publications (10 to 15, including the New York Times) and three local television news reports. The project also gained international attention via a German radio station's reporter who visited the site and conducted an interview with Pearson Court Square representatives.

From a generation viewpoint, NASA's Building 12 project has under-produced, but the project will provide data that will help researchers understand how to effectively site wind turbines in the urban environment, as well as assess performance and safety. This further exemplifies the multi-objective approach that assists in a project's success.

\section{NASA Building 12 - Houston, TX}

The Building 12 installation was originally designed as an effort to further the sustainability practices of NASA Johnson Space Center through a high-visibility education and demonstration project. It was hoped this project could provide onsite generation while aiding in compliance with mandates regarding renewable energy production at federal buildings. Completed in December 2014, the NASA Building 12 installation consists of four Urban Green Energy Eddy GT turbines. The project was constructed as part of a larger Building 12 renovation that included other sustainability initiatives such as a green roof. Developers originally intended to utilize Tangarie GALE 5-kW VAWTs, but the manufacturer went out of business after the order was placed. Although a resource assessment was conducted prior to turbine installation, project developers had already committed to the turbine purchase prior to its completion, resulting in the final installation being located in a low-wind-resource site. 


\subsubsection{The order in which objectives are prioritized can influence project outcomes.}

While it may be necessary to have multiple objectives for a single project, it is also important to understand the influence that objective prioritization can have on project outcomes. The impact of this type of decision can be seen with the Brooklyn Navy Yard turbine array. Project developers had to choose between siting the turbine installation where it would be most visible or where the resource was strongest. In this case, visibility was considered the primary objective, a decision that could have contributed to the overall underperformance of the installation. The Brooklyn Navy Yard developers did not have accurate pre-construction energy estimation tools; thus the energy impact of their decision to site for visibility was likely not completely transparent to them. In this case, project performance was greatly diminished by the selection of a very visible site.

\subsubsection{Potential liability and safety issues should be understood and addressed during the planning process.}

There are potential risks when people work on top of a building for turbine installation and servicing. There is also a possibility that ice or wind turbine parts could be shed and fall onto people or traffic. This was identified as a key challenge in NREL's Built-Environment Wind Turbine Roadmap (Smith et al. 2012). These risks may be no greater than other accepted risks for a large-building owner, but they may lie outside of standard insurance coverage. Additionally, while researching the case studies, NREL researchers found at least one BEWT project that involved active litigation between the project financial sponsor and the installer and turbine manufacturer. Conversely the safety and liability issues were not mentioned in the case studies except for requirements related to equipment survival during extreme wind speeds (e.g., NASA cited having to withstand 130-mph winds as part of the design criteria for the turbine and mounting) (Smith et al. 2012).

\subsubsection{Concerns regarding a project's impact on local aviation procedures can add unanticipated steps to the permitting process.}

While permitting for a vast majority of these projects seems to have been a straightforward process, project developers for two of the roof-mounted installations were required to ensure that the turbines would have minimal aviation impacts.

Due to the Boston Museum of Science's close proximity to Logan Airport and the significant project height (combination of building and turbine), project developers needed Federal Aviation Administration approval prior to installation. Similarly, the Twelve West installation required Federal Aviation Administration approval due to its significant project height (combination of building and turbine). Although this requirement did not stop either project from moving forward, it was a condition 
that no one anticipated and that developers for future projects should be aware of prior to beginning the permitting process.

\subsection{Project Costs Lessons Learned}

\subsubsection{Additional expenses related to installation in the built environment can create high- cost projects.}

BEWT installation costs are high due to the combination of logistics expenses, building reinforcement requirements, and extensive planning and permitting often required. Logistics of getting equipment and workers onto the roof and providing for safety can be a significant additional expense compared to ground mounting a small wind system. If a wind system is being added to an existing building that was not designed for it, the structural reinforcements required to distribute the load to the existing structure can often exceed the cost of the wind generators. The Boston Museum of Science experienced escalated project cost due to the design, materials, and construction of support structures necessary to safely deploy its rooftop installation. Nearly one-quarter of the project's $\$ 350,000$ budget (2009) was spent on structural steel, a larger portion of the budget than was utilized for project equipment (i.e., towers and turbines).

\subsubsection{The potential additional complexities of performing maintenance on BEWTs can lead to cumbersome and expensive practices.}

A variety of factors can influence the costs and effort needed to properly maintain a project: turbine type and size, tower type, building height and infrastructure, availability of qualified technicians and parts, and turbulence intensity (TI) of the wind resource. Depending on the turbine type and installation location, crane services may be required. Coordinating these services can lead to project downtime for unexpected issues as well as additional crane mobilization costs. The installation design should include a plan to not only access the turbines but also to remove and replace any part of the system, even the entire turbine assembly if required. Two of the projects reviewed experienced turbine maintenance issues: Detroit Metro Airport (lack of parts due to manufacturer bankruptcy) and Boston Museum of Science (fixed budget, unanticipated coordination, and lack of qualified local technicians). 


\subsection{Project Performance and Reliability Lessons Learned}

\subsubsection{Consolidation of small turbine manufacturers has been common and can lead to loss of warranty and difficulty in service parts availability.}

The rate of consolidation for small turbine manufacturers has made it difficult for some BEWT developers to obtain parts essential to keeping a system operational. Four of the five turbine manufacturers that were utilized in the Boston Museum of Science project have gone bankrupt since the turbines were installed, creating difficulties in maintenance and part replacements. Due to the original turbine manufacturer going out of business, NASA Building 12 project developers had to choose an alternative turbine manufacturer and model after placing the initial order. Detroit Metro Airport also experienced manufacturer viability issues. Airport officials are considering moving forward with the goal of keeping at least three turbines generating electricity by shutting down and borrowing parts from the remaining turbines. While some of the assets of these companies were purchased by other businesses and most of the turbines remain in production, the warranties and previously established contacts have largely been voided, further increasing costs and adding to maintenance complexity. Since most small wind generators are produced by small startup companies, this risk may be unavoidable. However, project developers may find it worthwhile to investigate the history and financial status of a turbine supplier.

\subsubsection{BEWT project performance is often over- estimated when compared with actual production.}

In every built-environment case study NREL conducted and in most examples from the Warwick wind trials (Encraft 2009), the predicted energy was over-estimated compared with actual results. This overestimation can stem from a variety of sources such as incorrect wind resource assumptions and no accounting for physical losses. Many of the case study stakeholders recommended a long-term onsite measurement program to assess the site winds. Additionally, the NASA Building 12 case study revealed that even with detailed measurements, the expected performance is well below what is predicted with the measurements. This indicates that the measurements combined with turbine power curve do not fully account for the potential energy at a site; other factors known as losses must be accounted for in the energy estimation process. 


\subsubsection{Current national and international standards do not reflect wind conditions often seen in the built environment.}

Certified turbines have been designed and certified to a national or international set of guidelines. These turbines generally incorporate the highest productivity and reliability standards offered by the distributed wind industry. These standards were, however, developed for turbines to be installed in open-field applications and may not be completely applicable for the built environment. While BEWT conditions may differ from the conditions specified in the standard, the use of certified turbines is still recommended as they are the most rigorously designed and tested turbines available on the market.

\section{Detroit Metro Airport - Detroit, MI}

Installed as a pilot program to determine whether small wind technology should be further deployed at the Detroit Metro Airport in Michigan, this installation originally consisted of six Windspire turbines. Of all the case studies compiled, this project is the only one that was not roof mounted; it was installed on airport property in an area among buildings that are taller than the turbines. Although actual production was not tracked, the project was originally estimated to generate approximately 2,000 kWh annually. Airport officials believe that when operating, the contribution has been significantly less than estimated. Hampered by maintenance issues and a lack of available parts due to manufacturer bankruptcy, according to airport officials the project never met expectations. 


\section{Recommended Practice}

This section discusses the general evaluation and planning process that is recommended for potential BEWT project stakeholders. Substantive documents exist that deal with this topic for traditional openfield projects, and we will reference them and highlight the differences between a BEWT project and a conventional open-field wind project. A BEWT project is subject to all of the criteria of an openenvironment project evaluation and more due to the additional complexities associated with the urban environment. The typical planning process for a standard small wind installation project ${ }^{5}$ includes the following phases:

- Understand customer needs through establishing baselines; develop project goals

- Perform a technical evaluation:

- Site evaluation

○ Turbine selection

○ Wind resource assessment

○ Production estimate.

- Estimate project costs

- Conduct a cost/benefit analysis.

The built environment adds new dimensions and challenges to these planning process phases. This document aims to illuminate those dimensions and challenges with the best available information. Although largely relevant to the installation of all small wind turbines, the following parameters must be considered even more carefully when siting BEWT projects:

- Wind resource

○ Wind speed frequency distribution

○ Predominant wind direction

○ TI

Inflow angles.

- Building characteristics and geometry

○ Building shape (square, rectangular, irregular)

- Roof shape (flat roof, pitched roof, parapets)

○ Building orientation with respect to predominant winds

○ Building structural considerations.

- Turbine technology

○ Turbine safety limits

- Wind speed

- Turbulence

- Extreme direction change.

○ Turbine orientation (HAWT vs. VAWT)

\footnotetext{
${ }^{5}$ See Small Wind Site Assessment Guidelines: http://www.nrel.gov/docs/fy15osti/63696.pdf
} 
○ Tower height.

- Installation and maintenance

○ Initial construction costs

O Ongoing operations and maintenance costs.

- Building occupant comfort and safety

○ Noise emissions

○ Vibration emissions

○ Turbine failure projectile zone (TFPZ) (Olsen and Preus 2015).

\subsection{Establish Baselines and Goals}

Energy projects can be a significant investment of time and money. It is therefore recommended that developers of potential projects define clear goals and gather enough information to make informed decisions with a rigorous cost-benefit approach. Potential project goals can include any or all of the following:

- Low-cost energy generation

- Carbon reduction targets or renewable energy targets ${ }^{6}$

- LEED certification credits

- Marketing or public relations value for a commercial building

- Support of local and/or onsite generation

- Utilization of federal, state, and utility incentives

- Education and outreach.

Some benefits may be harder to quantify, but being aware of the full range of outcomes is important for project sponsors. The following key steps will help ensure a well evaluated project:

- Identify reasons and goals for undertaking a BEWT project (e.g., carbon reduction, cost of energy reduction, etc.)

- Establish baselines and expectations for the goals identified (e.g., baseline current energy and carbon/environmental footprints)

- Perform a broad-based feasibility study to match goals with the appropriate projects and technology

- Conduct a detailed cost-benefit analysis on the most viable options.

\subsection{Perform a Technical Evaluation}

Once project goals have been identified, the technical evaluation begins. The following key parameters should be considered in addition to any identified goals for BEWT projects:

- Project siting

- Comfort and safety/liability

- Wind resource

\footnotetext{
${ }^{6}$ BEWT projects may not be optimal for obtaining carbon reduction or renewable energy targets as those are usually tied to energy production.
} 
- Turbine certification and selection

- Energy production.

Each of these items is discussed in further detail below.

\subsubsection{Project Siting}

Properly siting a wind turbine in the complex urban environment requires knowledge of several parameters of the site, the turbine, and long-term project operations. Every turbine may respond differently to the same wind in terms of power production, loads, and reliability. A successful BEWT project developer combines these factors with knowledge of the building structure, defined goals, and long-term operations and maintenance plans. When identifying suitable locations for a BEWT project, the following parameters should be accounted for:

- Installation, operations, and maintenance

- Comfort and safety of building occupants, equipment safety, and liability

- $\quad$ Building geometries (see Section 4.2.3.3)

- Wind resource as a driver for energy production and reliability (see Section 4.2.3)

- Other project goals such as visibility.

\subsubsection{Installation, Operations, and Maintenance}

BEWT projects are not usually ground-mounted projects. As such, they require special considerations that tend to drive project costs higher than traditional open-field projects. Wind turbines are dynamic systems experiencing dynamic loads that can vary with the wind powering the turbines. These loads require specialized foundations, either as part of the building design process or as an installation retrofit. This can result in extra engineering, permitting, materials, and labor costs that can increase the total installed cost and the levelized cost of energy (LCOE).

A long-term maintenance plan should also be developed with safe, cost-effective turbine access included. If the installation is building mounted, additional time and cost should be planned for the logistics of providing service support. The exact level of additional time and cost depends on the access requirements and what methods are available for accessing the nacelle. Maintenance access will also need to balance productivity, visibility, and other goals. Limiting the number or magnitude of expensive crane mobilizations and men working at height can greatly improve project success and decrease LCOE.

\subsubsection{Comfort and Safety of Building Occupants, Equipment Safety, and Liability}

The comfort and safety of people in the vicinity of the BEWT project should also be considered. The BEWT will emit sound and vibration as part of the normal operation, which can transfer through the building structure. Developers should inquire with prospective turbine manufacturers as to the turbine's certified sound levels, dynamic motion of the machine, and any potential sound/vibration mitigation options for mounting or operation. The structural engineering analysis should include consideration of sound and vibration transfer.

There are currently no accepted design methodologies or standards for BEWTs or their installation, which means there are limited means to provide confidence in the safety and suitability of turbine or installation design. We recommend that BEWT project developers engage a qualified third party to evaluate the turbine and the installation in light of the site-specific resource to minimize the potential for premature turbine failure or reduced reliability. Potential BEWT projects should include analysis of 
where components or ice throw may land if dislodged (the TFPZ). The site-specific fatigue and extreme loads combined with the traffic density of the TFPZ will yield an overall risk model of the BEWT deployment. The TFPZ, potential turbine loads, and the risk profile can all be affected or minimized by properly siting the turbine for safety and reliability.

The liability of turbine deployment and/or failure is still largely unknown and remains site specific. Consulting a qualified legal expert to assess any liabilities that may arise from deployment of a BEWT project is recommended.

\subsubsection{Wind Resource}

Accurately assessing the wind resource in the built environment is perhaps the single most challenging element of a BEWT project. The wind resource combined with turbine parameters affects energy production as well as turbine reliability and safety. The distinction for BEWT projects is that when a fluid (in this case air) flows over buildings, trees, or other structures (generically called roughness elements), they extract momentum from the air. This extraction of momentum results practically in lower mean wind speeds and higher mixing known as turbulence. These roughness elements do occur in traditional open-flow field projects but typically with a much lower density and impact on the wind.

The current tools used for modeling the resource of small wind projects can have very high uncertainty in complex terrain. BEWTs are considered to be located in extremely complex terrain, and there is a demonstrated over-prediction of energy outcomes in the urban environment (Encraft 2009).

Additionally, the current commonly used models may not provide the complete atmospheric parameters required to properly estimate turbine production and reliability. ${ }^{7}$ Based on these findings and the observation that none of the projects highlighted in the case studies produce near the values predicted, even for projects in which detailed computational fluid dynamics (CFD) modeling was conducted, we recommended in situ measurement program as the best option to quantify the wind resource. Beyond measurements, high-fidelity physics-based modeling offers the most likely successful resource quantification approach. Advanced modeling approaches such as CFD or a large eddy simulation (LES) are required to properly characterize the site-specific resource. The challenge is that even the advanced models don't capture the full array of flow physics and are expensive to run, potentially costing more than the wind turbine itself. There are ongoing R\&D activities within academic and industry institutions to be able to cost effectively perform these investigations, but they are largely limited to the realm of research at this time.

Research gathered through the International Energy Agency (IEA) Wind Task 27: Wind turbines in highly turbulent environments ${ }^{8}$ demonstrates a multitude of challenges for prospective BEWT designers. These challenges include different turbulent decay characteristics, inflow angles, and more (Tabrizi et al. 2014.) Figure 4 is an example of the complexity of wind flow around buildings. The primary flow direction of this figure aligns with the $\mathrm{x}$ axis and goes from right to left over and around the building. The top, sides, and lee of the building demonstrate highly turbulent and non-laminar flow.

\footnotetext{
${ }^{7}$ A full list of important atmospheric and turbine variables to consider in BEWT projects is included in Table 3 . Summary of IEC 61400-2 Wind Characteristics that Differ between Built-Environment and Open-Field Sites

${ }^{8}$ International Energy Agency, Task 27: http://www.ieawind.org/task_27 home_page.html
} 


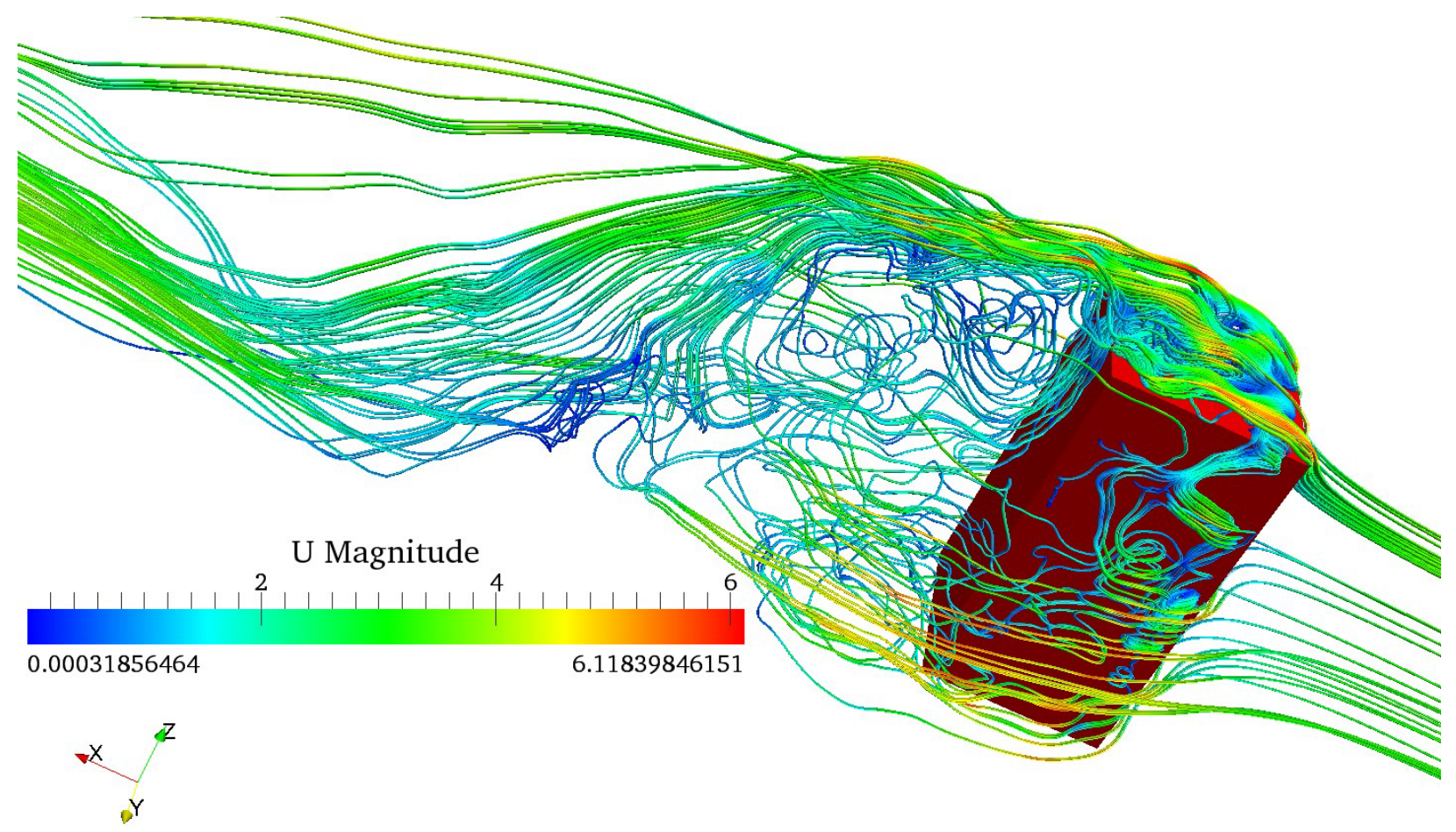

Figure 4. LES simulation of wind flow around building (Toja Silva 2015)

There are, however, some emerging rules of thumb that although not validated may help project sponsors if they choose to undertake a BEWT project. These rules mainly address how high the turbine tower needs to be with respect to the building in order to escape the highly turbulent and variable winds associated with installing wind turbines in close proximity to buildings or other structures.

All BEWT projects are likely to be in high-TI environments even if they are ground mounted. For a ground-mounted installation, start with standard wind resource assessment techniques (as outlined in the Small Wind Site Assessment Guidelines), paying special attention to object shading adjustments and displacement height ${ }^{9}$ issues. If the object is a large building close to the wind turbine, an object shading tool such as the Danish Wind Shade Calculator ${ }^{10}$ will not work well. Unless the wind turbine is higher than the building, little wind will reach the turbine from the direction of the building.

The cubical configuration of a simple building will have a zone of accelerated flow velocity and large vertical flow components at the upwind edge of the building, a large region of separated flow and eddies on the top surface and in the leeward side of the building (Figure 4). The height of the region of separated flow on top of the building can be approximated with CFD analysis, an empirical method (Wilson 1979), or measurements. It is important to note that the turbulence characteristics of the wind before it arrives at the building will impact the actual wind behavior, which will impact the accuracy of CFD and empirical analysis. Since the wind can come from any direction, optimal siting is complex because the region of separated flow will also change based on wind direction and building geometry. It requires that the flow be analyzed for at least all directions with significant wind energy input.

\footnotetext{
${ }^{9}$ Displacement height is the adjusted ground level height for calculating apparent hub height based on ground clutter that raises the height at which there is nearly zero wind velocity (e.g., in forests or densely developed areas with many buildings). ${ }^{10}$ The Danish Wind Shade Calculator is a free tool that can be used to run shade analysis for wind projects; available at http://www.motiva.fi/myllarin_tuulivoima/windpower\%20web/en/tour/wres/shelter/index.htm
} 
For building-mounted BEWT projects, the same displacement height principles as with any standard wind turbine siting apply, except that the height of local buildings will create that displacement height. For applications in which production, safety, and reliability are important, the difficult work is determining the best location on the building and the expected wind resource at that location. A great source of information on wind resource distribution on a rectangular building is Building-Mounted Micro-Wind Turbines on High-Rise and Commercial Buildings (Blackmore 2010). This publication provides analysis of normalized wind speed and TI by location across the top of rectangular buildings of height 80 meters at a distribution of wind directions. Some results are provided for shorter buildings. The work is based on wind tunnel experiments at a scale of 1:200. Limited comparison to CFD and empirical rules is described. While this work is very valuable, it should be used as a guide for siting since the results are averaged and few buildings are simple rectangles. A few cautionary comments and prime points that are useful guides are:

- Taller buildings generate higher separation bubbles.

- Reaching 90\% of average ambient wind speed happens at a lower height than reduction of TI to $110 \%$ of ambient.

- Unless installing rotors less than 2 meters diameter, the heights for reaching acceptable wind speed and TI should be the bottom of the rotor-swept area.

- There is no optimal location for all wind directions.

- While Blackmore uses an average of all four corners and other reference locations for rule-of-thumb minimum heights, these heights vary significantly from one point to the other, so this is not good guidance for micrositing.

- Contour plots of normalized wind speed and TI are for the model of an 80-meter-tall by 40-meterwide by 20 -meter-deep building with a flat top and no structures on the top.

- It does not appear that Blackmore investigated the results at multiple wind speeds and the effect different wind speeds may have on the height of the separation bubble.

While this information does not provide a simple set of rules to microsite a wind generator on a building, it does provide some basic guidance.

To use this information for micrositing, we suggest one of the following options:

- If the building is generally rectangular and a high-quality wind rose is available, use the information provided by Blackmore to identify areas of the building that have acceptable TI values (18\% or below) at the maximum turbine height you can consider. This will need to be performed for each significant wind direction. Determine if any sites are available, and then evaluate whether they are structurally capable of supporting the turbine and tower.

- Select some good candidate sites that are open and structurally capable of supporting the turbine. Use the TI contours suggested by Blackmore and the wind speed to determine the minimum acceptable tower height. Due to the large uncertainty caused by differences in the real building, the local environment, and the models used in the wind tunnel, this should be used for preliminary assessment only, and we recommend that wind speed and direction measurements be taken at the specific location.

- If the building has a more complex shape or there are significant other large buildings in the area, a CFD model of the building and surrounding area will give a more accurate picture of the wind resource. It will also show the wind speed distribution over the building. Multiple simulations will be needed to understand wind flow from each primary wind direction. While this analysis can be 
expensive, the results are likely to be more accurate, providing a better assessment of the resource at locations of interest.

If having a reliable energy projection is important, then site-specific wind speed and TI data collection at any proposed turbine location is required, regardless of the initial site assessment methods. If the rotor for the turbine being proposed is more than 2 meters in diameter, we also recommend that data be collected at least at the bottom and top of the rotor swing to determine TI at both levels and shear between them. It is also valuable to measure the vertical component of the wind resource. Very high shear can exist in the transition zone from the separation bubble to linear flow found on the top of flat roofs, and a passively yawed turbine can have significant yaw error when operating in a high-shear environment, further reducing energy capture.

If turbine visibility is a more important goal than performance, start with acceptable locations for visibility and do the wind resource analysis in those locations. While the best locations for energy production may have been eliminated, this analysis will allow developers to determine the minimum acceptable height and approximate energy production. In some cases, siting turbines for appearance will result in a project that has virtually no energy production value. ${ }^{11}$ Wind generators that are mounted on the top of parapets are especially sensitive to mounting in relationship to wind orientation, as can be seen in the Brooklyn Navy Yard case study.

If monitoring the system or the ability to determine if it is producing power according to the manufacturer's published power curve is desired, it will be necessary to have a reference anemometer that measures the wind speed entering the turbine. In a conventional open-flow field installation, it is common to install an anemometer at 2 to 4 rotor diameters upwind in the primary wind direction at hub height. With a building-mounted wind generator, that may not give an accurate result and in some cases may be physically impossible. Investigate alternative siting, such as cross wind from the turbine planned location. Then install the monitoring anemometer at the same time as the anemometer in the turbine location. This allows a direct comparison of the wind speed at both locations. Analysis will be required to assess the correlation by wind direction. A related issue for monitoring and performance is that many commercial building roofs have large heating ventilating and air conditioning, or HVAC, systems on the roof. In addition to being physical obstacles to air flow, this equipment can significantly impact air flow to the turbine or anemometer.

\subsubsection{Frequency Distribution}

Numerous measurement experiments have demonstrated that the wind resource in the built environment is relatively energetically weak (Encraft 2009, Tabrizi et al. 2014). The wind speed frequency distributions, which are an indicator of energy content in the wind, are usually shifted to the lower wind speeds, which results in lower energy production. This is driven by the fundamental physics of fluid flow and turbulence. As shown in Encraft 2009, some tall buildings can escape or minimize the impacts of the turbulent boundary layer created by the urban environment. Figure 5 demonstrates the relationship between measured wind speeds and the turbine power curve at the NASA Johnson Space Center Building 12 site. The overlap between the two data distributions represents the potential energy at a given site. The NASA site with low winds is a relatively poor power-producing site.

\footnotetext{
${ }^{11}$ It is worth noting that if the ultimate goal of a project is to demonstrate a dedication to green energy or sustainability, turbines may be installed in a location that maximizes visibility over production. This placement can lead to turbines that spend a large amount of time motionless and do not produce much energy. The end result could be a perception that wind turbines do not work, enforcing the opposite impression than was desired.
} 


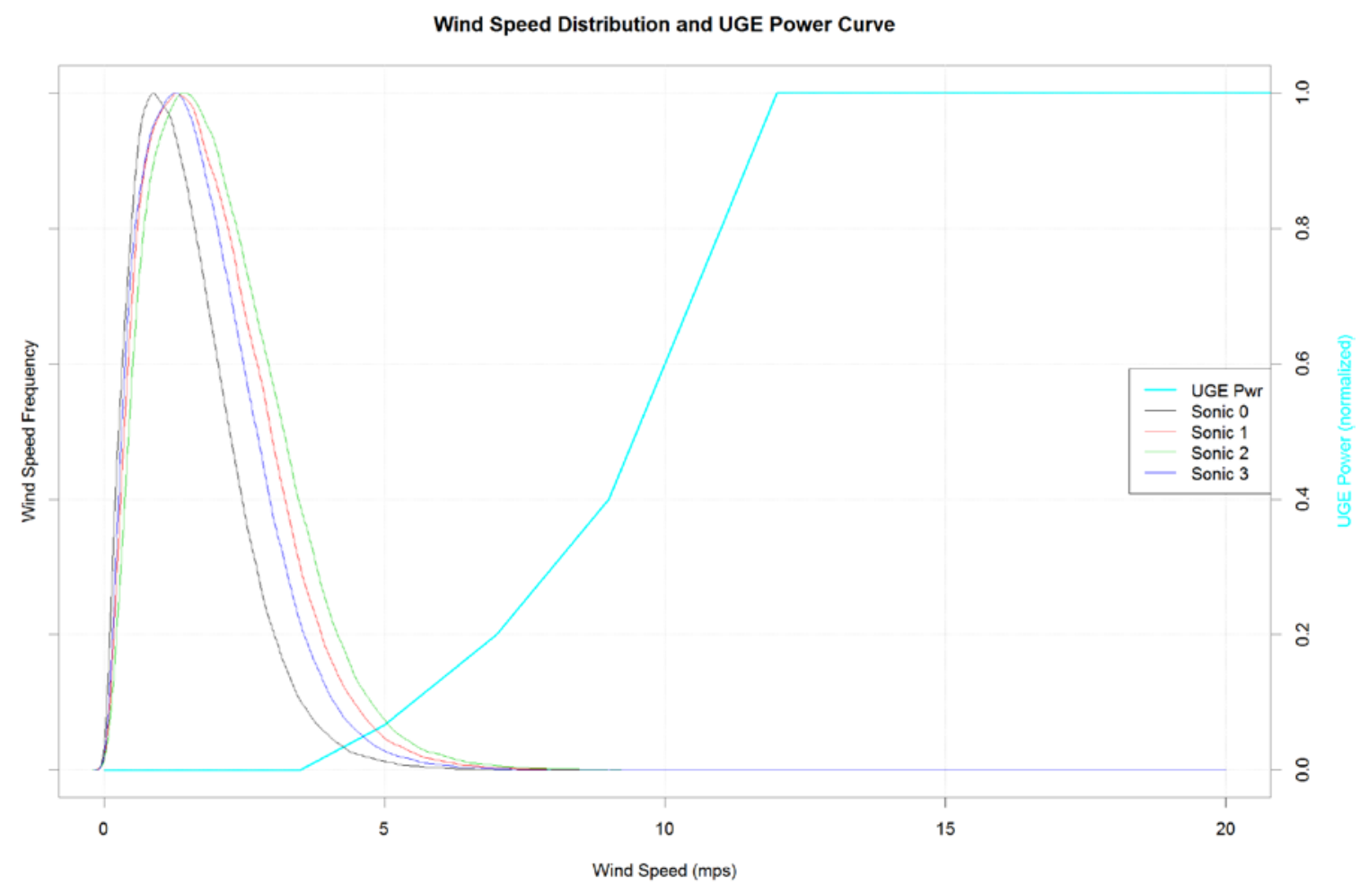

Figure 5. NASA Building 12 frequency distribution of the wind speeds at the four planned turbine locations and power curve for the UGE turbines that were installed

\subsubsection{Turbulence}

Turbulence in wind applications relates to the variability of the winds. The traditional International Electro-technical Committee (IEC) definition of turbulence for wind energy applications is described as TI.

$$
T I=\frac{\sigma_{U}}{\bar{U}}
$$

where $\bar{U}$ is mean wind velocity and $\sigma_{U}$ is standard deviation of the wind velocity

The Normal Turbulence Model (NTM) specifies the appropriate level of TI by wind speed as part of the turbine design process for the IEC 61400-2 standard. Installing turbines at locations with a TI above the NTM will likely result in high turbine maintenance and reduced reliability. Although sites in the built environment with a TI at or below the NTM can likely be found, this will be difficult because of the highly turbulent nature of winds in these areas. Measurements taken at several built-environment installation sites highlight this complication, registering TI well above the NTM guidance. High TI will lead to increased fatigue loads over time, which has implications for component reliability, maintenance costs, safety, and overall turbine lifetime. Figure 6 shows an example of the low wind and higher turbulence measured in the built environment and how it often exceeds the NTM from the IEC 61400-2 classification. This is typical in urban environments due to the high concentrations of roughness elements, which lead to turbulent flows. The IEC 61400-2 standard includes a very useful informative section, Annex L, which also deals with turbines in the built environment. ${ }^{12}$

\footnotetext{
${ }^{12}$ IEC 61400-2:2013 http://asc. ansi.org/RecordDetails.aspx?action=pl\&ResourceId=488010\&ResourceGuid=5a323577b074-48a8-a8e5-69d307be5e0f\&NativeKey_I=IEC+61400-2+Ed.+3.0+b\%3a2013\&NativeKey_II=1507253
} 


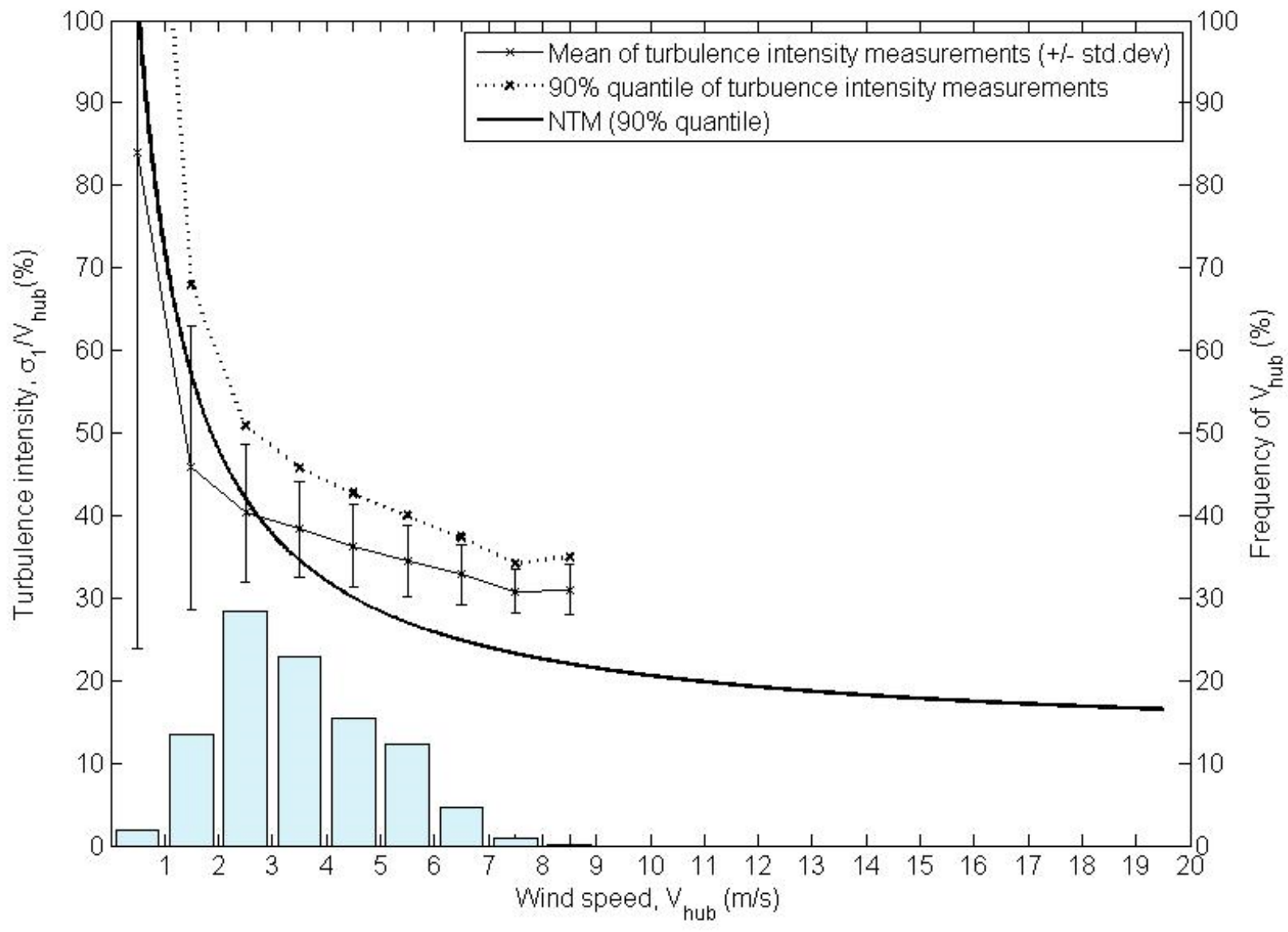

Figure 6. Turbulence intensity and wind distribution, $2 \mathrm{~m}$ above rooftop in Melville, Western Australia, during January-February 2009 (Whale, Ruin, and Tokuyama 2012)

\subsubsection{Wind Direction and Variability}

Wind direction and variability are very important considerations for siting and the design of a wind turbine. While most turbine designs can swivel around the top of the tower to match incoming winds, the wind direction in the built environment can be more stochastic and change more quickly than in typical ground-mounted installations. The practical implications of rapidly changing wind direction are that energy production is likely to be reduced and higher loads will be placed on a turbine. Figure 7 shows CFD simulations, which demonstrate the directional variability of resource on a building based on wind direction. This figure demonstrates that depending on the incoming wind direction and speed, a variety of mounting heights are needed to escape the building's turbulent effects. In general, as you increase the ratio of turbine height to building roof area, the suitable area for turbine placement on this square rooftop increases. 

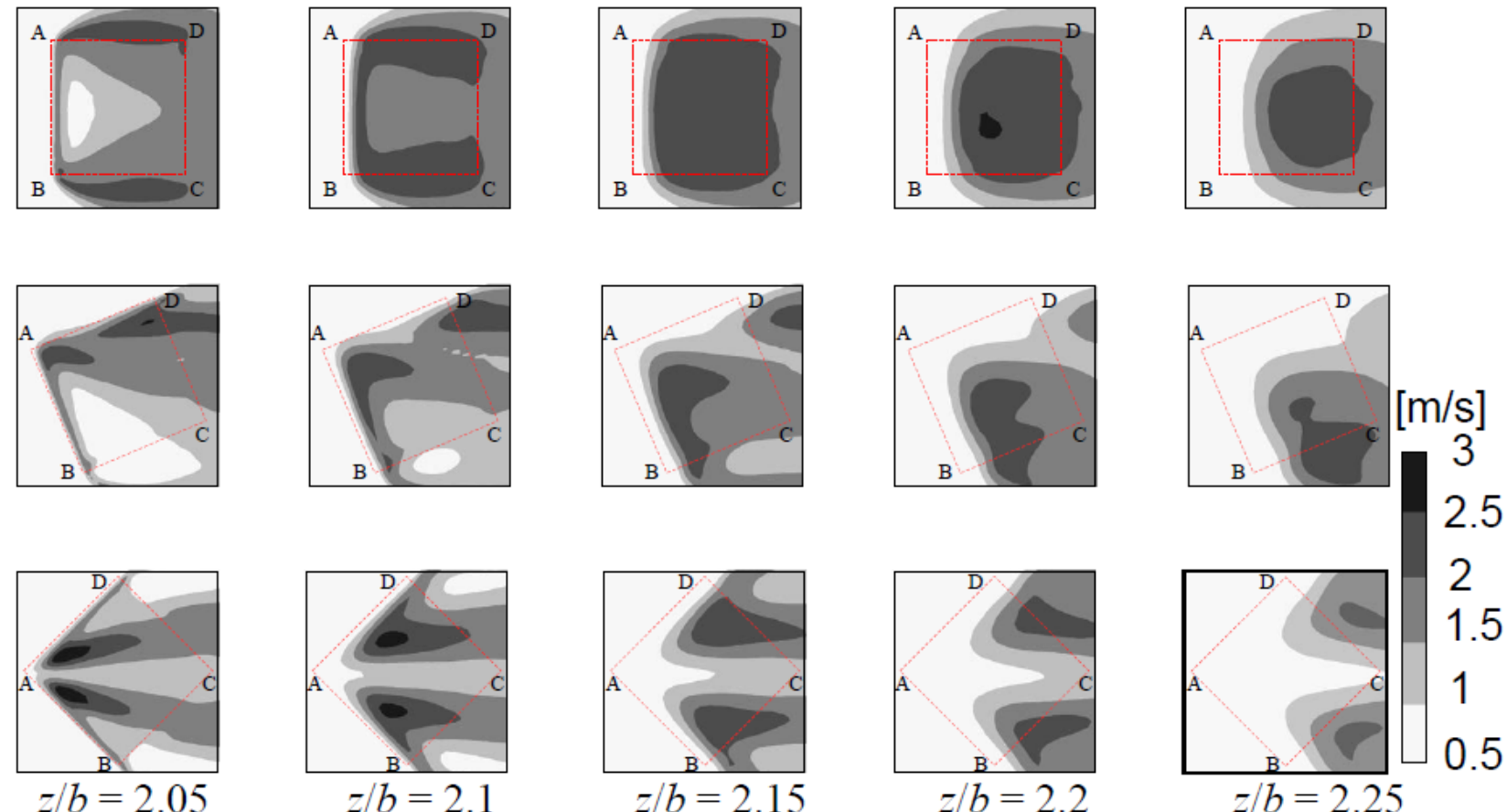

( $2 \mathrm{~m}$ above roof) (4 $\mathrm{m}$ above roof) (6 $\mathrm{m}$ above roof)( $8 \mathrm{~m}$ above roof)(10 $\mathrm{m}$ above roof)

\section{Figure 7. Standard deviation of stream-wise wind velocity based on building orientation and the ratio of building height (z) versus breadth (b) (Kono and Kogaki 2012)}

\subsubsection{Turbine Certification and Selection}

The main standard for small wind turbine design is the IEC 61400-2. This standard describes appropriate input parameters and calculation approaches for turbine loading and resultant expected lifetime. There are other national standards, such as the American Wind Energy Association's small wind turbine standard 9.1 used in the United States, but most of them rely on the fundamental methods in the IEC 61400-2. We strongly recommend that turbines that have been certified to the IEC or other appropriate national standard be used, especially for projects in the built environment. This will help ensure that the turbine is reliable and productive. Additionally, many of the U.S. incentive schemes are increasingly requiring the use of certified turbines.

While the use of certified turbines is recommended, there are still some important caveats to understand about the current standards and certification approach. Built environments, in contrast to traditional open environments, are likely to be characterized by lower wind speeds, higher turbulence, and the potential for significant off-axis flow such as vertical wind velocities. The current standards for design and testing of wind turbines assumes relatively low values for these conditions, such as a TI of below $18 \%$.

Installation of even certified turbines at sites outside of the conditions set forth within the standards will in all likelihood result in high turbine maintenance and reduced reliability. Additionally, turbines are typically tested in low-turbulence sites with no upwind obstructions, so the structural loading and power generation may not represent the performance in the built environment. There is also little track record of any turbine in this environment, so the reliability and performance impacts are unknown. A wind turbine certified to the IEC standards is considered certified, but only for limited conditions that a BEWT site would not adhere to. Therefore it is currently impossible to have a BEWT-certified turbine. However, installing a turbine that has been certified to an international or domestic standard is much more likely to provide a better result than a turbine that has not gone through such a process. Finally, as urban environments are often characterized by denser populations than open-field environments, and installing a turbine in these environments yields significant new safety concerns that may not be 
accounted for in the current wind turbine designs that were never intended to be deployed close to people or in urban environments. Table 3 is a summary of the IEC 61400-2 standard wind characteristics, which differ between the built environment and traditional open environments.

Table 3. Summary of IEC $61400-2$ Wind Characteristics that Differ between Built-Environment and Open-Field Sites

\begin{tabular}{ll}
\hline \multicolumn{1}{|c}{ IEC Chapter Index } & \multicolumn{1}{c}{ Topic } \\
\hline 3.56 & Wind profile, wind shear law \\
\hline 3.6 & Wind speed distribution \\
\hline 6.2 & Small wind turbine classes \\
\hline 6.3 .1 & Inclination flow \\
\hline 6.3 .2 .1 & Wind speed distribution \\
\hline 6.3 .2 .2 & Normal Wind Profile Model \\
\hline 6.3 .2 .3 & Normal Turbulence Model \\
\hline 6.3 .3 .2 & Extreme Wind Speed Model \\
\hline 6.3 .3 .3 & Extreme Operating Gust \\
\hline 6.3 .3 .4 & Extreme Direction Change \\
\hline 6.3 .3 .5 & Extreme Coherent Gust \\
\hline 6.3 .3 .6 & Extreme Coherent Gust with Direction \\
\hline
\end{tabular}

\subsubsection{Energy Production}

Developing energy projections starts with a resource assessment (typically annual or multi-year), including quantities such as wind speed and wind direction. The energy estimation process then combines that information to the power curve of the wind generator and then applies adjustments to address losses that may degrade turbine production. Losses can include a variety of impacts such as icing, turbine downtime, and electrical efficiencies. To maximize the accuracy of the energy projection, it is necessary to have an accurate, certified power curve and a systematic survey of the potential losses. Since power curves are generated in low-TI environments, there is some unavoidable uncertainty for a high-TI environment.

If the turbine must operate some of the time in a TI outside its design specification, it can have an impact on energy production. There are no definitive methods for adjusting turbine energy production for varying turbulence levels. There are, however, a number of investigations into the impacts of turbulence on wind turbine power curves, including the Power Curve Working Group. ${ }^{13}$ The impact of turbulence on power production is site specific, but preliminary estimates for utility-scale turbines show as much as a $30 \%$ deviation from expected power with varying turbulence levels (Blodau 2013). As of the writing of this document, methods in test and realistic correction methods, such as turbulence renormalization, are better understood. In lieu of rigorous verified methods, common practice in the distributed wind turbine industry is to multiply the estimated energy by the TI (5) and deduct that from the energy production estimate based only on wind speed resource. This applies to ground-mounted BEWT installations as well.

\footnotetext{
${ }^{13}$ The Power Curve Working Group is a wind industry collaborative that aims to facilitate stakeholder collaboration in order to acknowledge, address, and ultimately resolve the question of "non-standard" (now commonly called "Outer-Range") inflow conditions on wind turbine power curves; see www.pcwg.org
} 


\subsection{Estimate Project Costs and Conduct a Cost-Benefit Analysis}

Project economics are often important criteria among many that project stakeholders will use to evaluate the feasibility of a BEWT project. We recommend that the project stakeholders evaluate the total project costs and expected energy output. That information can then be compared with onsite electric loads and power costs in light of other potential renewable energy or energy efficiency solutions. Additional value streams such as marketing, education, or carbon reduction should be considered and quantified to evaluate the viability of a BEWT project. The evaluation of the energy production capability and associated value will have high uncertainty. No projects assessed for this report have met their energy projection estimates. Guidance presented here should improve the accuracy of energy estimates.

BEWT projects can have higher costs due to:

- More complex and difficult wind resource evaluation requiring advanced modeling and/or extensive on site measurements

- Structural integration with the building

○ Specialized engineering and materials to understand, design, and implement building strengthening

○ Special mounting to isolate turbine vibrations from the building.

- Complex installation and maintenance logistics

- A non-optimal operating environment leading to premature turbine wear or failure

- Increased liability and insurance costs.

Once you have an energy projection, calculating the value of the energy is relatively straightforward (this topic is discussed in the Small Wind Site Assessment Guidelines). For a BEWT project, much of the project value may come from meeting other goals. The value of each of those goals may be difficult to quantify, and they may exceed the value of the energy generated. 


\section{Summary and Conclusions}

BEWT projects are wind energy projects that are constructed on, in, or near buildings. These projects can be attractive because they present an opportunity for distributed, carbon-free generation. However, there are distinct challenges with this emerging application. In order to mitigate performance risk and manage expectations, NREL recommends that the following key steps be incorporated when planning a BEWT project:

- Establish baselines and develop project goals

- Perform a technical evaluation:

○ Project siting

○ Safety/liability

$\circ$ Wind resource

- Energy production/turbine specification

$\circ$ Energy value and incentives.

- Estimate project costs

- Conduct a cost/benefit analysis

The built environment adds new dimensions, costs, and challenges to these planning process phases. Although relevant to the installation of all small wind turbines, the following parameters must be considered more carefully when siting BEWT projects:

- Wind resource

- Building characteristics and geometry

- Turbine technology

- Installation and maintenance

- Building occupant comfort and safety.

It should also be noted that based on several key factors (i.e., wind speeds are typically lower and costs for implementing projects in built environments are typically higher), projects in the built environment can be difficult to justify on a cost of energy or energy-offset basis. Understanding the expected production of a wind turbine in the built environment is a very complex undertaking; the use of onsite resource measurements combined with high-fidelity models is likely the only way to truly understand the expected turbine production.

\subsection{Case Studies and Lessons Learned}

In general, developers of BEWT projects we examined as part of our case studies and in external studies such as the Warwick wind trials ${ }^{14}$ have had mixed results. Energy predictions rarely meet preconstruction expectations, and the turbines are often shut down or removed early due to vibration, noise, or reliability concerns. The Warwick wind trials consisted of 26 BEWT deployments, which had a variety of challenges. Although there was some variability in the performance and reliability of machines, the general results were quite poor. Overall capacity factor was reported at $0.85 \%$ and is noted as being indicative of BEWT projects, including real losses and use problems. In addition to the low performance, it was also noted that wind speeds at 16 out of the 26 sites were $\sim 40 \%$ lower than the model predictions. Additionally, even when measurements were available and used to predict power, the

\footnotetext{
${ }^{14}$ http://www.warwickwindtrials.org.uk/2.html
} 
turbines produced less energy than seemed apparent. This speaks to the importance of having not only robust models and measurements but also a good energy prediction model that can account for physical losses.

The NREL case studies contain examples of successful BEWT projects from a stakeholder perspective; however, it should be noted that these projects include goals for public relations or educational values in addition to energy production goals that are rarely met.

The case studies also demonstrate that BEWT projects with clear goals and informed planning were the most likely to be deemed successful by the stakeholders. In order to maximize the chances of success for a BEWT project, considerable effort and upfront planning are required, including evaluating the wind resource's strength and quality (TI, inflow angle, extreme direction change). The tools for estimating the wind resource on the top of a building are expensive and not well validated, so onsite data collection is advised. Special care must also be used to assess the TI at perspective sites since the impact of high TI on performance and reliability is not well understood. In addition, operation in high-TI environments can increase maintenance costs and shorten turbine life. No standards exist for testing turbines for the BEWT environment, so such installations result in a wind generator operating in an environment for which it was not designed or tested.

Siting the turbine in a built environment can also lead to additional costs not typically associated with the deployment of small wind generators. Unless the building has been designed to allow for the mounting of a specific wind generator, costly structural work may be required. The cost of engineering and building upgrade efforts may exceed the cost of the wind generators. Unless the installation is designed to provide easy access for service and maintenance, including removal and replacement of the entire turbine if necessary, then maintenance may also be more expensive than standard projects. Depending on the cash value of the energy produced, a poorly planned installation can end up not generating enough revenue to cover the turbine maintenance expense. A turbine that falls into disrepair is more likely to suffer a catastrophic failure which, in the built environment, may have increased liability associated with potential injury or other collateral damage.

Because installations in the built environment are currently not common, it is important to establish with the manufacturer that they are willing to warranty and support the wind generator in the environment where it will be installed. Current wind turbine design standards and certifications are designed around more conventional turbine installation environments, so even a certified turbine may be operating outside of its design envelope. Although not just confined to turbine suppliers providing technology to the built-environment market, a wind turbine manufacturer's ability to meet long-term warranties or even supply replacement parts is dependent on its overall financial health and should not be assumed.

This document defined BEWT projects, discussed the current state of the industry, laid out a recommended practice, and demonstrated real projects through a variety of case studies. The motivations for the implementation of these projects are varied, and depending on those overriding goals, not all of the projects were reported as being successful by their owners. None of the case study projects met their energy production estimates, largely due to the complexity of conducting accurate resource and production assessments in complex built environments. Additionally, although there may be some initial considerations that the installation of the turbine on top of a building may offset the cost of towers, the costs of deploying turbines in the built environment are typically more expensive than originally estimated. In the eyes of the project owners, some of the case study projects have been successful based on all of the goals set forth for the projects, such as raising awareness of sustainability. The experiences of some of the case study project developers left them skeptical about wind energy in general. 
In conclusion, based on the findings associated with the case studies analyzed (especially the NASA Building 12 work funded by the U.S. Department of Energy), NREL recommends a thoughtful and thorough evaluation of any BEWT project to ensure the ultimate results match with pre-determined goals. Developers considering BEWT projects should understand that, based on the limited number of case studies that could be assessed as part of this report, projects in the built environment are likely to have lower power production values and higher related costs than would normally be assessed based on experience with turbine installations outside of the built environment. 


\section{Glossary}

Built environment

Built-environment wind turbine

(BEWT)

Computational fluid dynamics (CFD)

Extreme direction change

Frequency distribution

Horizontal-axis wind turbine (HAWT)

Large eddy simulation (LES)

Levelized cost of energy (LCOE)

Micrositing

Permitting
An urban or suburban setting, characterized by buildings and other structures that typically result in lower wind speeds, higher turbulence, and the potential for significant off-axis flow, such as vertical wind velocities.

Wind turbines that are typically $100 \mathrm{~kW}$ and smaller, located in an urban or suburban environment (built environment). They may be mounted on buildings or among buildings.

A branch of fluid mechanics that uses numerical analysis and algorithms to solve and analyze problems that involve fluid flows.

A measure of how variable the wind direction at a particular site might be.

Distribution of wind speeds that may be a modeled distribution using a statistical function or a table of a recorded history of hours of wind at each wind speed for a site.

A wind turbine designed with the axis of rotation around a horizontal shaft, typically with a propeller-like configuration.

Mathematical model for turbulence used in computational fluid dynamics.

The total cost of installing and operating a project, expressed in dollars per kilowatt-hour of electricity generated by the system over its life.

The process of selecting a wind turbine location and determining the likely wind resource (speed and turbulence) available after considering all possible impacts, such as topography, ground cover, and obstacles, and their location relative to the tower's location. Part of selecting a location includes all of the other factors besides wind, such as construction access, land-use restrictions, aesthetics, access to a power system, etc.

The process of obtaining legal permission to build a project, potentially from a number of government agencies, but primarily from the local building department (i.e., the city, county, or state). During this process, a set of project plans is submitted for review to assure that the project meets local requirements for safety, sound, aesthetics, setbacks, engineering, and completeness. The permitting agency typically inspects the project at various milestones for adherence to the plans and building safety standards. 
Site assessment

Small wind turbine

Turbulence intensity

Vertical-axis wind turbine (VAWT)

Wind shear
The act of evaluating a site to determine a favorable location for a wind turbine, which includes assessing the expected wind resource and potential turbine performance at that location.

A wind turbine that has a rating of up to 100 kilowatts, typically installed near the point of electric usage such as near homes, businesses, remote villages, and buildings.

A basic measure of turbulence that is defined by the ratio of the standard deviation of the wind speed to the mean wind speed. For wind energy applications, this is typically defined as a 10-minute average wind speed and standard deviation based on 1-second samples. Turbulence intensity is important for wind energy applications because it has implications for power performance and turbine loading.

A turbine designed with the axis of rotation around a vertical shaft and two prevalent configurations: Darrieus, which is an egg-beater style with primarily lift aerodynamics, and Savonius, a split-barrel style with primarily drag-based aerodynamics.

The difference in wind speed and direction over a relatively short distance in the atmosphere. Wind shear can be broken down into vertical and horizontal components, with horizontal wind shear seen across storm fronts and near the coast, and vertical shear seen typically near the surface (although also at higher levels in the atmosphere near upper-level jets and frontal zones aloft). 


\section{References}

Blackmore, P. (2010). Building-Mounted Micro-Wind Turbines on High-Rise and Commercial Buildings. IHS BRE Press. United Kingdom.

Blodau, T. (May 2013). Review of Inner/Outer Range Proposal. PCWG Meeting \#3, Repower HQ, Hamburg, Germany. http://www.pcwg.org/proceedings/2013-05-30/01-Introduction-06-Review-ofOuter-Range-Proposal-Tomas-Blodau-REPower.pdf

Boston Museum of Science Wind Lab. (2015). Energized! Exploring Renewable Energy. http://legacy.mos.org/energized/museum-wind.php

Detroit Metro Airport. (April 22, 2010). "Earth Day Breezes into Detroit Metro Airport -- Airport Authority Begins Testing New Wind Energy Technology." News release. http://www.wcaa.us/Portals/WCAACorp/WCAA\%20Documents/PDFs/NR Windspire Event 22APR2010 POST.pdf

Dopp, T. "NYC Opens 1st Building-Mounted Wind Turbines at Brooklyn Yard." Bloomberg, April 9, 2009. http://www.bloomberg.com/apps/news?pid=newsarchive\&sid=aOiCpp9Xilpk

Encraft. (2009). Warwick Wind Trials Final

Report. http://www.warwickwindtrials.org.uk/resources/Warwick+Wind+Trials+Final+Report+.pdf

Galbraith, K. “Assessing the Value of Small Wind Turbines.” New York Times, September 3, 2008. http://www.nytimes.com/2008/09/04/business/04wind.html?pagewanted=all\&_r=2

Greeson, E. (October 8, 2010). "RNP Visits ZGF Architects for Rooftop Renewables Tour." Renewable Northwest. http://www.rnp.org/node/rnp-visits-zgf-architects-rooftop-renewables-tour

Kono, T.; Kogaki, T. Numerical Simulation Analysis of Wind Conditions over a Rectangular PrismShaped Building for Mounting Small Wind Turbines. IEA Wind Task 27 Meeting, Dundalk, Ireland, September 25-27, 2012.

NASA. (August 26, 2015). Our Planet Is Changing. We're On It! https://www.codegreenhouston.org/dmdocuments/resources/gbrc panel_jsc 8 26_15.pdf

Olsen, T.; Preus, R. (2015). Small Wind Site Assessment Guidelines. National Renewable Energy Laboratory, NREL/TP-5000-63696. http://www.nrel.gov/docs/fy15osti/63696.pdf

Rabkin, D.; Tomusiak, M. (September 2014). Museum of Science Wind Turbine Lab Project History and Three-Year Performance Report. Boston Museum of Science. http://www.mos.org/sites/develvis.mos.org/files/docs/about-us/Three-Year-Performance-Report.pdf

Smith, J.; Forsyth, T.; Sinclair, K.; Oteri, F. (2012). Built-Environment Wind Turbine Roadmap. National Renewable Energy Laboratory, NREL/TP-500050499. http://www.nrel.gov/docs/fy13osti/50499.pdf

Tabrizi, B.; Whale, J.; Lyons, T.; Urmee, T. (2014). Suitability of the von Karman and Kaimal spectrum for the structure of the turbulence in the built environment in terms of rooftop small wind turbine applications. Submitted to Journal of Wind Engineering and Industrial Aerodynamics. 
Tokuyama, H. (March 2011). Analysis of Field Data Regarding Extreme Wind Direction Changes on an Urban Rooftop Site. IEA Wind Task 27 meeting, Madrid, Spain, March 3-4, 2011.

Toja Silva, F. (April 2015). CFD Simulation of the Wind Flow around Buildings: Case Study in Soria (Spain) - Computational Issues. IEA Wind Task 27 Meeting, University of Applied Sciences Technikum Wien, Vienna, Austria.

Tomusiak, M. (July 26, 2011). "Museum of Science Analyzes Rooftop Turbines." Interstate Renewable Energy Council. http://www.irecusa.org/2011/07/19769/

Whale, J.; Ruin, S.; Tokuyama, H. (April 2012). Turbulence Intensity Values at Potential SWT Sites in Non-open Terrain. International Energy Agency Task 27 Meeting, Ithaca, New York, USA.

Wilson, D. (1979). "Flow patterns over flat-roofed buildings and application to exhaust stack design." ASHRAE Transactions 1979: 85 (2): 284-295.

Zemke, J. "Metro Airport Installs First Wind Turbines.” Metromode, April 29, 2010. http://www.secondwavemedia.com/metromode/devnews/metroairportwindturbines0161.aspx 


\section{Bibliography}

International Energy Agency, Wind Task 27, Small Wind Turbines in High Turbulence Sites, http://www.ieawind.org/task_27 home_page.html, accessed December 24, 2015.

Tabrizi, A.; Whale, J.; Lyons, T.; Urmee, T. (2014). Performance and safety of rooftop wind turbines: use of CFD to gain insight into inflow conditions. Renewable Energy, 67, pp. 242-251.

Toja-Silva, F.; Colmenar-Santos, A.; Castro-Gil, M. (August 2013). Urban wind energy exploitation systems: Behaviour under multidirectional flow conditions - Opportunities and challenges. Renewable and Sustainable Energy Reviews, Volume 24, pages 364-378.

Toja-Silva, F.; Peralta, C.; López, O.; Navarro, J.; Cruz, I. Roof region dependent wind potential assessment with different RANS turbulence models. Renewable Energy, under review.

Whale, J. Designing and Installing Small Wind Turbines for the Built Environment. IEA Wind RD\&D Task 27 Extension, National Wind Technology Center, Louisville, CO, May 2014. 


\section{Appendix A: Case Studies}

\section{Twelve West}

Location: Portland, OR

Turbine type: Skystream 3.7

Number of turbines: 4

Installation date: 2009

Building integrated: Roof mounted (23-story building, mounted on 45-foot poles, blades at an elevation of 82 meters)

Estimated production: $\sim 9,000 \mathrm{kWh}$ yearly, or $\sim 1 \%$ of the building's electricity

Actual production: $\sim 5,500 \mathrm{kWh}$ per year

Cost: $\$ 20 \mathrm{~K}$ per turbine; $\$ 240,000$ for entire installation (mounting pads, engineering, etc.)

Incentives: $30 \%$ federal Investment Tax Credit in cash at project completion

Payback: $\sim 40$ years

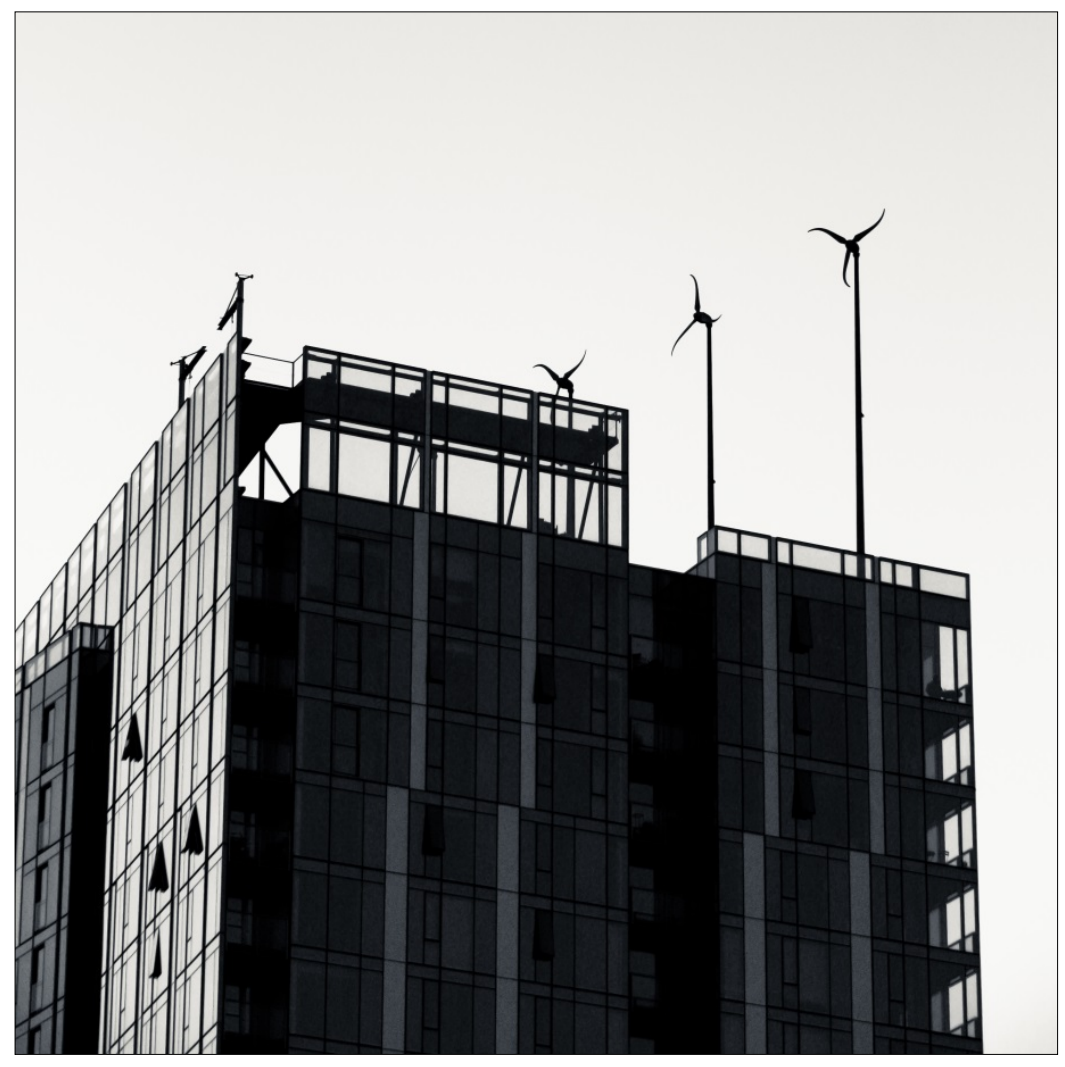

Figure 8. Twelve West wind turbine installation in Portland, OR. Photo from Flickr 4852149002
Maintenance record: Have had issues with Turbine \#3 (does not spin on occasion and must be restarted). This is under control with building management.

What was the primary project objective? Raise awareness about renewable energy. Elevate the visibility of the building. Underscore the building's sustainability commitment.

Did the installation meet those goals? Rooftop wind in urban environments is challenging and has not evolved as much as we had hoped; however, all other objectives were met, and we consider this installation a success.

Given your experience and the lessons you've learned, what suggestions would you give to another organization determined to develop a similar project? Take advantage of and leverage as many resources as you can. Make sure the turbine project is a good

fit for your site; a token array that never spins will be detrimental when it comes to public opinion. Pay careful attention to turbine siting. A prominent wind specialist from the Netherlands advised us on 
turbine placement based on the wind patterns in the area. Research the products well, and get comfortable with the fact that the manufacturer may go out of business (many of these companies are start-ups), which makes replacement/repair and warranty enforcement difficult.

\section{Additional Notes}

Turbine choice: Due to the limited data regarding built environment wind installations, project developers didn't know what to anticipate in terms of turbine selection. None of the turbines researched had long track records for this type of installation, so the group conducted a significant investigation to identify what turbines would be best to use. Project developers conducted in-depth research during their turbine selection process, visiting multiple vendors and installations prior to selecting Southwest Windpower Inc. as the turbine supplier. One factor that influenced the selection was the company's compliance with European certification standards (Greeson 2010).

Development process: The wind turbines were part of a larger project: the design and construction of a 23-story LEED Platinum-certified mixed-use apartment and office building. Project developers decided to utilize solar and wind energy to help reach their LEED goal. The turbines were integrated into the building design early in the process, allowing the building's developers time to consult with experienced wind energy professionals to properly assess the site prior to installation. During this period, the developers conducted a thorough site assessment that included flow pattern simulations conducted at the Oregon State University's Aero Engineering Lab.

The project developers also had to engage in discussions to address Federal Aviation Administration concerns related to the combined height of the building and project.

Public interest: Project developers believe the installation's visibility and the attention it has created for renewable energy and sustainability have been phenomenal. The installation has helped the building become a unique and recognizable feature in the city of Portland.

Sound impacts: Since the project is located directly above the building's penthouse units, special consideration had to be given to reducing the potential sound impacts of the installation. This increased costs but was essential to overall project success. 


\section{Detroit Metro Airport}

Location: Detroit, MI

Turbine type: Windspire 1.2

Number of turbines: 6

Installation date: 2010

Operational status: As of July 2015, one turbine had a broken inverter and was not operational. Airport officials have relocated two turbines from the original location and will be moving forward with the goal of keeping at least three generating electricity by borrowing parts from the remaining turbines.

Building integrated: No

Estimated production: 2,000 kWh per year

Actual production: Project was never tracked. When operating, contribution has been minimal.

Cost: $\$ 75,000($ Zemke 2010$)$

Incentives: No incentives provided

Payback: Production is not being recorded, so it's not feasible to estimate simple payback.

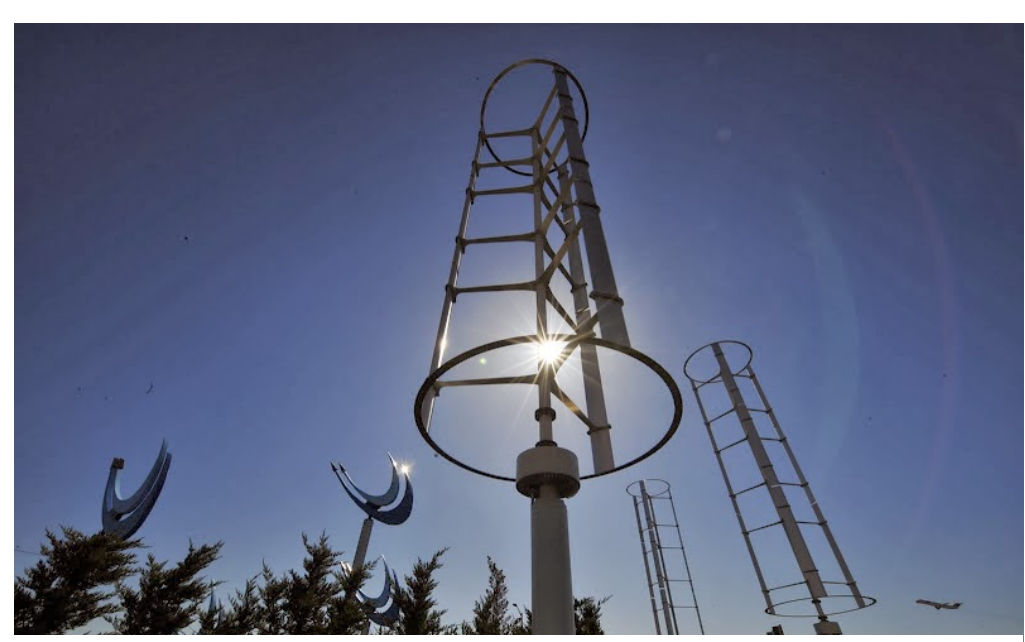

Figure 9. Detroit Metro Airport Windspire installation. Photo from Wayne County Airport Authority
Maintenance record: Issues (inverters, bearings) from the beginning of the project until now. Manufacturer is bankrupt. It's difficult to find and maintain parts.

What was the primary project objective? Did the installation meet that (those) goal(s)? The project was a pilot program to determine whether the technology should be further deployed at the airport (Detroit Metro 2010). In terms of energy production, the project did not meet expectations. This is primarily due to maintenance issues, as well as lowerthan-advertised production (developers

were told that the turbines were not as efficient as other models and that they should not anticipate much production due to the site, but they are doubtful of efficient production even with a good resource). The project was installed during Earth Day 2010 and was featured in multiple articles and news stories. Airport officials say there is continued interest in the project from a visitor perspective and that they continue to be contacted about the project from those interested in installing similar projects.

Given your experience and the lessons you've learned, what suggestions would you offer to another organization determined to develop a similar project?

- Try to get guarantees of energy generation rates, not just anticipated estimates based on computer modeling. 
- Make sure the manufacturer-approved sales/installation vendor is experienced and capable of doing the work.

- Work with established manufacturers so as not to run into repair/replacement part issues if the company folds.

\section{Additional Notes}

Although Bryan Wagoner, Wayne County Airport Authority's Environmental Program Administrator, was not in charge at the time, he believes that Small Wind Certification Council certification would have been influential in terms of technology selection if it had been available.

Wagoner also believes that additional research prior to installation could have benefitted the overall project. "If we had to do it over again, we would do a more planned project where metering and that kind of stuff were included in the initial design; where we did some studies beforehand and maximized the wind. I think with that we'd get a much better result."

\section{Museum of Science}

Location: Boston, MA

Number of turbines: 9

Turbine type: Windspire 1.2-kW, Skystream 3.7, Swift, Proven 6, AeroVironment AVX1000 (bank of 5)

Installation date: 2009

Building integrated: roof mounted

Estimated production: $20,498 \mathrm{kWh}$ per year (15\% installed capacity)

Actual production: Cumulatively, the wind turbines average 4,229 kWh of electricity per year (Rabkin and Tomusiak 2014) ( 20\% of what was originally estimated)

Cost: $\sim \$ 350,000$ (Tomusiak 2011)

Incentives: Massachusetts Clean Energy Center (formerly known as the Renewable Energy Trust) provided a $\$ 300,000$ grant for purchase and installation. Site and resource assessment were funded through a \$50,000 grant from the Kresge Foundation (Tomusiak 2011). 


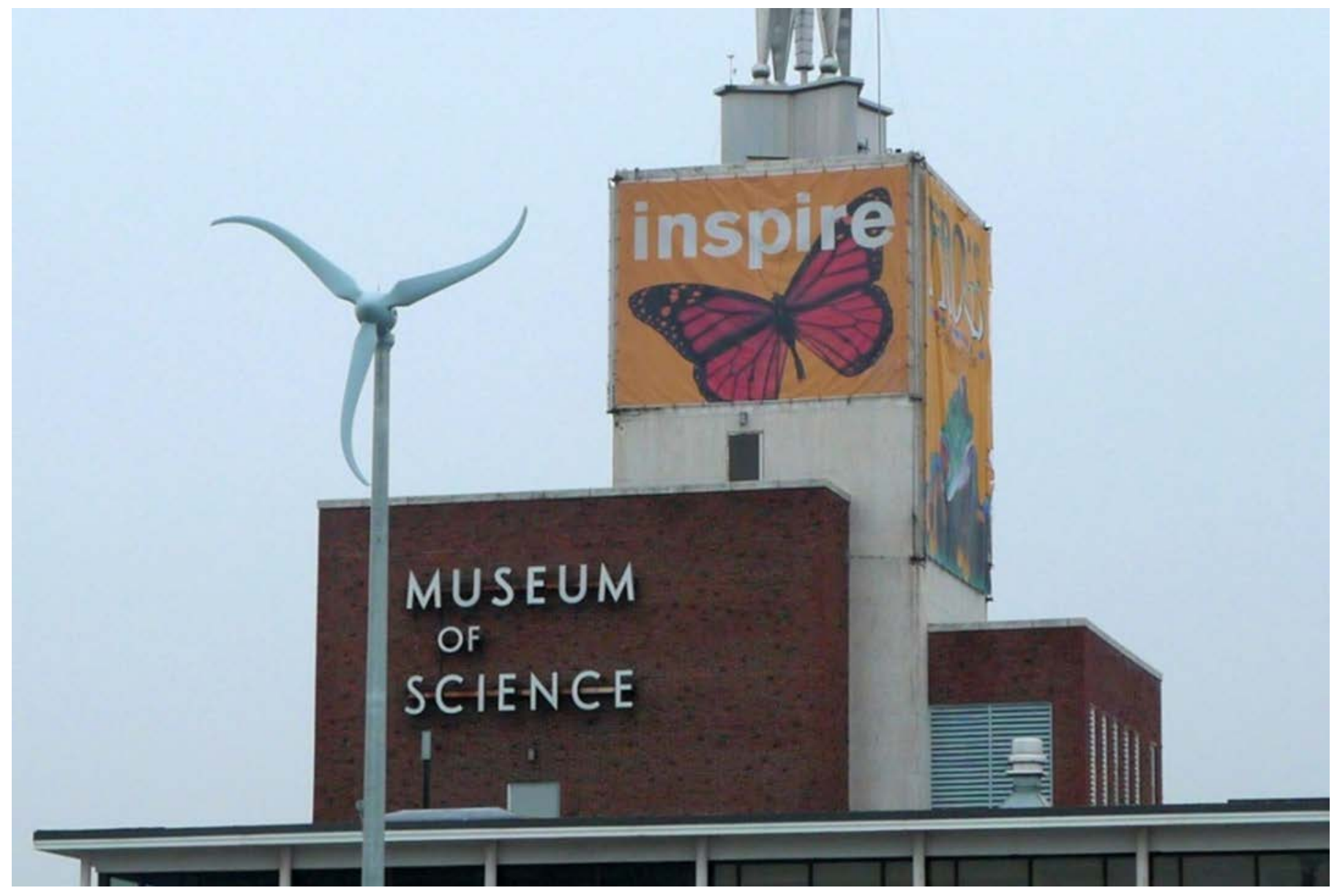

Figure 10. Skystream installation at the Boston Museum of Science. Photo from Boston Museum of Science, NREL 18006

Payback: Assessment showed that wind profile and site assessment would not yield monetary payback within 20 years. The project went forward as a test lab.

\section{Maintenance record:}

- Skystream: Out of service last 3 months of 2012. Periodically stops and restarts for months at a time. Currently operational

- Windspire: Initial inverter issues. Standard model replaced by extreme wind model in 2011. In 2014, the mounting connection failed in high wind. Currently non-operational

- Proven 6: Wiring adjustment in 2013. Currently operational

- AVX1000: Recurring inverter and hardware issues during first year of operation (Rabkin and Tomusiak 2014). Currently operational

- Swift: Brake adjustment 3 months after installation. Currently operational.

What was the primary project objective? Did the installation meet those goals? The primary objectives of the Museum of Science Wind Lab included:

- Creating a roof-top location where a variety of commercially available small wind turbines could be tested in the built environment

- Providing data and experience for the general public and industry professionals 
- Constructing an exhibit that would become a landmark for both the city and region

- Generating clean energy while making a statement on its importance (Rabkin and Tomusiak 2014).

Years of project experience, wind data, and performance data have been shared with more than 1,300 people so far (Boston Museum of Science 2015). These include the general public; industry professionals; and university classes from Massachusetts Institute of Technology, Worcester Polytechnic Institute, Boston University, Northeastern, and Emerson. Of all the energy-saving and sustainable practices the museum employs, the turbines are the most visible to the public. The project has been producing clean energy that is used onsite with only two confirmed bird strikes since 2009 and none of the other problems people often fear (sound, vibration, ice-throw, safety, aesthetics, wildlife issues, etc.).

\section{Given your experience and the lessons you've learned, what suggestions would you give to another entity determined to develop a similar project?}

- Establish well-defined project goals.

- Communicate with stakeholders early and often to gain their support.

- Measure the wind resource as close to hub height as practical in order to better understand the energy potential of your wind regime and any possible restrictions due to structural factors of the building or the surrounding environment.

- Installation sites may need to be a compromise between wind, building structures, and perceived public safety.

- Roof-mounting turbines is expensive compared to conventional installations, primarily due to higher costs of engineering and structural steel supports (Rabkin and Tomusiak 2014).

- Maintenance can be a more complex issue than originally anticipated. Roof access and access to skilled technicians is a major long-term concern. Consider how quickly and affordably you can reproduce installation circumstances prior to establishing a project.

\section{Additional Notes}

During the permitting of the project, developers had to engage in discussions to address Federal Aviation Administration concerns related to the combined height of the building and project and proximity to Logan International Airport. Other concerns, all resolved before installation, included permitting by Cambridge and Boston, location in a historical district, location in a wetland, views from neighboring residential high-rises, different roof structures built over decades, and the perception of public safety.

Project developers said that the installation has not received any complaints related to sound or vibration, even though the largest turbine is located above the museum's Omni Theatre. 


\section{Brooklyn Navy Yard}

\section{Location: Brooklyn, NY}

Number of turbines: 6

Turbine type: AeroVironment AVX $1000(1 \mathrm{~kW})$

Installation date: 2008

Building integrated: Roof mounted

Estimated production: 14,400 kWh (estimates based on a sustained wind speed of $29 \mathrm{mph}$ )

Actual production: Over the first 192 days of the project: $126.92 \mathrm{kWh}$. Estimated production for that time period was $6,269 \mathrm{kWh}$.

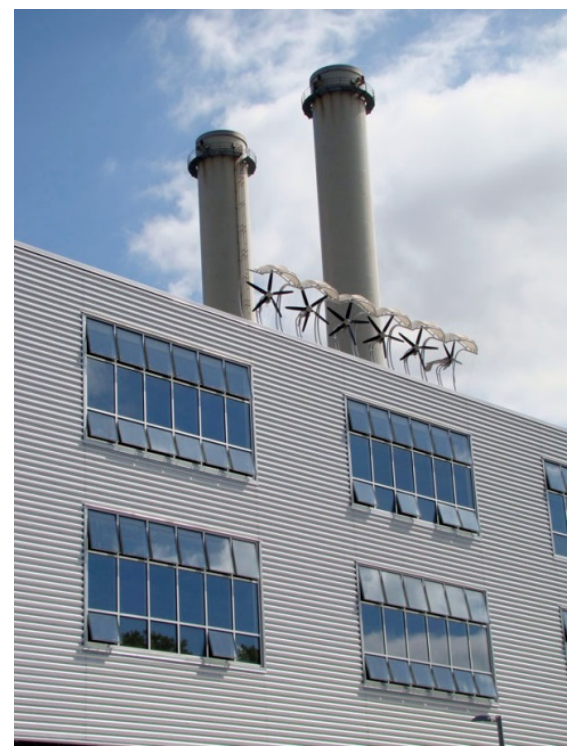

Figure 11. Brooklyn Navy Yard wind turbine installation. Photo from Flickr 2874788682
Cost: $\$ 6,500 /$ turbine (Galbraith 2008)

Incentives: N/A

Payback: N/A

Maintenance record: N/A

What was the primary project objective? Did the installation meet that (those) goal(s)? I believe the goals were primarily to promote the emerging wind technology, create a highly visible indication of the building's emphasis on sustainable design, and hopefully cover the costs of the installation over a reasonable amount of time based on energy savings. The first two goals were met but the third fell short.

Given your experience and the lessons you've learned, what suggestions would you offer to another airport or municipality determined to develop a similar project? Personally, before I consider wind technology on a future project, I would want to gather real-world data on wind speeds in the project location over an extended period. Mockups of the building geometry would be useful as well. I believe wind speed was the primary reason why our third goal (cover the costs of the installation over a reasonable amount of time based on energy savings) was not met.

The balance between visibility and strongest resource also has to be considered. During the development of this project, a choice had to be made between siting the turbine installation where it would be most visible or where the resource was strongest. In this case, visibility was given priority, which could have contributed to the overall underperformance of the project.

\section{Additional Notes}

The wind turbine was part of a larger project: the design and construction of the three-story, 89,000square-foot Perry Avenue building. The development was the first multi-story structure in the nation to be classified as a "green industrial facility" by the U.S. Green Building Council (Dopp 2009). 
The location did not provide the necessary wind speeds, with the exception of a few minutes each day. This resulted in an insignificant amount of power production.

Due to high maintenance costs and poor system performance, the owners have not kept the installation in working order or continued to track data.

\section{Pearson Court Square}

Location: Long Island City, New York

Turbine type: VisionAIR5 (Urban Green Energy)

Number of turbines: 3

Installation date: Spring 2014. Fully operational as of summer 2015

Building integrated: Roof mounted

Estimated production: $\sim 6,000 \mathrm{kWh}$ annually, depending on wind conditions and nearby site obstructions

Actual production: Too early to determine; system recently began generating

Cost: $\sim \$ 185,000$ total project cost, including installation of additional significant steel structural support

Incentives: New York State Energy Research and Development Authority; project also qualified for the Investment Tax Credit

Payback: Will not know until after a year or more of operation

Maintenance record: System needed to be adjusted to resolve vibration and noise issues. These need to be monitored as the turbines were installed on the roof of a multi-family building with many residents.

What was the primary project objective? Did the installation meet that (those) goal(s)? Project objectives included: Furthering the building's sustainable practices, marketing, and onsite energy generation. It is still too early in the process to determine how well the installation generates energy, but the other project objectives were met. In terms of marketing, during the project's initial launch and leasing phase, it was highlighted in numerous domestic publications (10-15, including the New York Times) and three local television news reports. The project also gained international attention via a German radio station's reporter who visited the site and conducted an interview with Pearson Court Square representatives.

Given your experience and the lessons you've learned, what suggestions would you give to another entity determined to develop a similar project?

The delay between installation and being fully operational was due in part to the interconnection approval process with the local electric utility company. Speak with local utility companies regarding interconnection early in the development process. Determine whether the local utility has requirements that must be met prior to interconnection in order to ensure timely operation.

Project intent should be more than generation. With a project that consists of three small wind turbines, the amount of generation under the best circumstances is limited. The project's additional objectives of 
furthering the building's overall sustainability and the increased visibility via the project's marketing value allowed the installation to be considered successful even if generation proves to be limited.

\section{Additional Notes}

Project developers utilized the company Pfister Energy to install the turbines. Pfister was the recommended installer by Urban Green Energy, manufacturers of the turbine selected for the project. While the installers had significant experience constructing other sustainability installations, they did not have experience installing these Urban Green Energy turbines. The developers found it interesting that no one had really done these projects before; it was difficult to find experienced installers.

\section{NASA Building 12}

The NASA Building 12 project is unique among the case studies as it involved detailed pre-construction and post-construction measurements. NREL researchers initiated a measurement campaign consisting of multiple rooftop anemometers and other atmospheric instrumentation located on the prospective turbine pad mounts and in the immediate rooftop vicinity. The Building 12 measurement program consisted of two phases: Phase $1^{15}$ is the pre-construction measurement campaign, and Phase 2 is the postconstruction measurement campaign. The full installation and commissioning documentation and datasets are available. ${ }^{16}$ The power data for Phase 2 was measured by the NASA enterprise Supervisory Control and Data Acquisition system and contains inputs directly from the turbine inverters. As of the writing of this document, Phase 2 data collection is ongoing, so this report contains a subset of the total data.

Location: Houston, TX

Turbine type: Eddy GT (Urban Green Energy) 1 kW

\section{Number of turbines: 4}

Installation date: December 2014

Building integrated: roof mounted

Estimated production: $\sim 1,250 \mathrm{kWh}$ annually (NASA 2015)

Actual production: In March 2015, the turbines produced $0.11692 \mathrm{kWh}$. Additional time and data are needed to determine the total production for the first year.

Cost: $\sim \$ 100,000$ (not including electrical infrastructure)

Incentives: N/A

Payback: Project developers believe the installation will not yield any monetary payback.

Maintenance record: Software update required. NASA is currently waiting on the installer and equipment manufacture to provide the update.

\footnotetext{
${ }^{15}$ Phase 1 data are available at http://en.openei.org/doe-opendata/dataset/nasa-building-12-wind-turbines-phase-1-data

${ }^{16}$ http://en.openei.org/wiki/NASA_Building_12_Wind_Turbines 


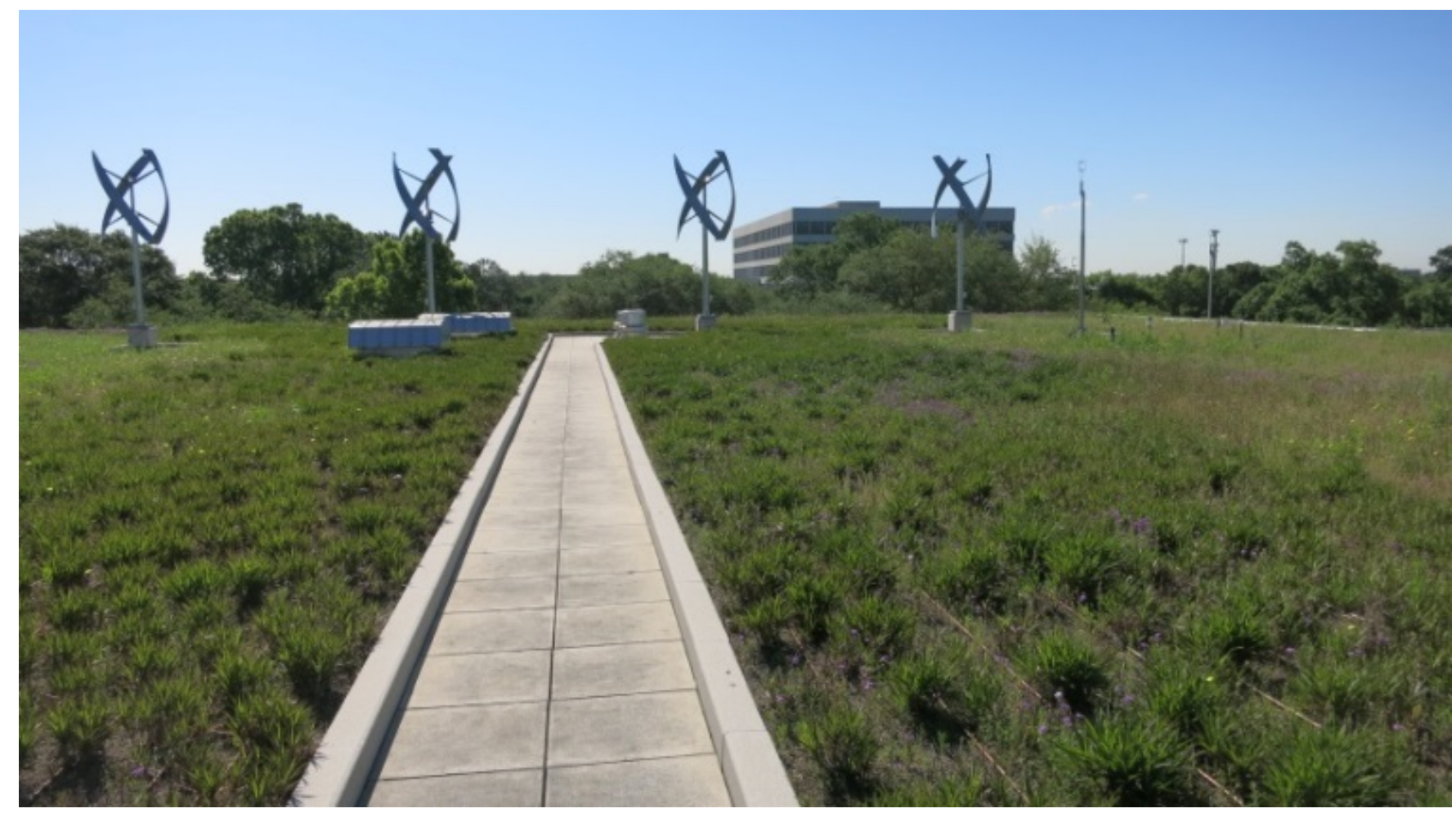

Figure 12. NASA Building 12 wind turbine installations. Photo by Dave Jager, NREL

What was the primary project objective(s)? Did the installation meet that (those) goal(s)? The primary objectives of the Building 12 installation include:

- Construct a high-visibility continuation of the facility's sustainability efforts

- Provide an educational and demonstration project that utilizes a new form of renewable technology

- Produce onsite generation

- Comply with mandates regarding renewable energy production at federal buildings.

Project developers feel that the installation did not meet all of its goals primarily due to the location's low wind resource, which led to an overall underperformance of the installation.

Given your experience and the lessons you've learned, what suggestions would you offer to another entity determined to develop a similar project?

If you are serious about the amount of energy your project will produce, you should conduct a thorough assessment of the location's resource prior to moving forward with equipment purchase and installation.

- Project location is key to project having access to resource. Alternative siting options were extremely limited due to the multitude of historical buildings at Johnson Space Center and the funding being tied directly to Building 12 renovations. Building 12 is located in the middle of an industrial building and office park. The building is approximately two stories (30') and is surrounded by several taller multi-story buildings (up to $111^{\prime}$ ') at most orientations. Due to the surrounding structures and their influence on the local wind resource, the location is not optimal for this type of installation. The following image shows the elevation of Building 12 and its surrounding buildings. 


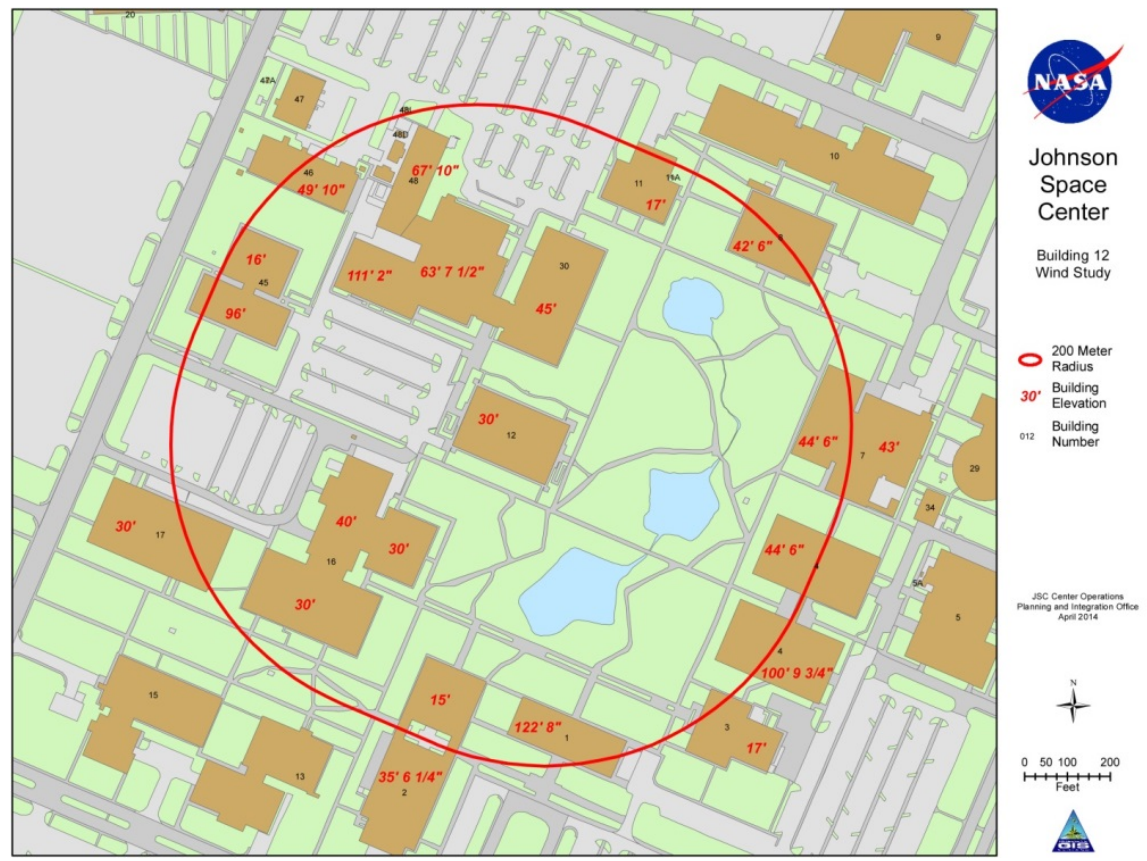

Figure 13. A part of the NASA Building 12 project assessment, this elevation map shows the height of surrounding structures.

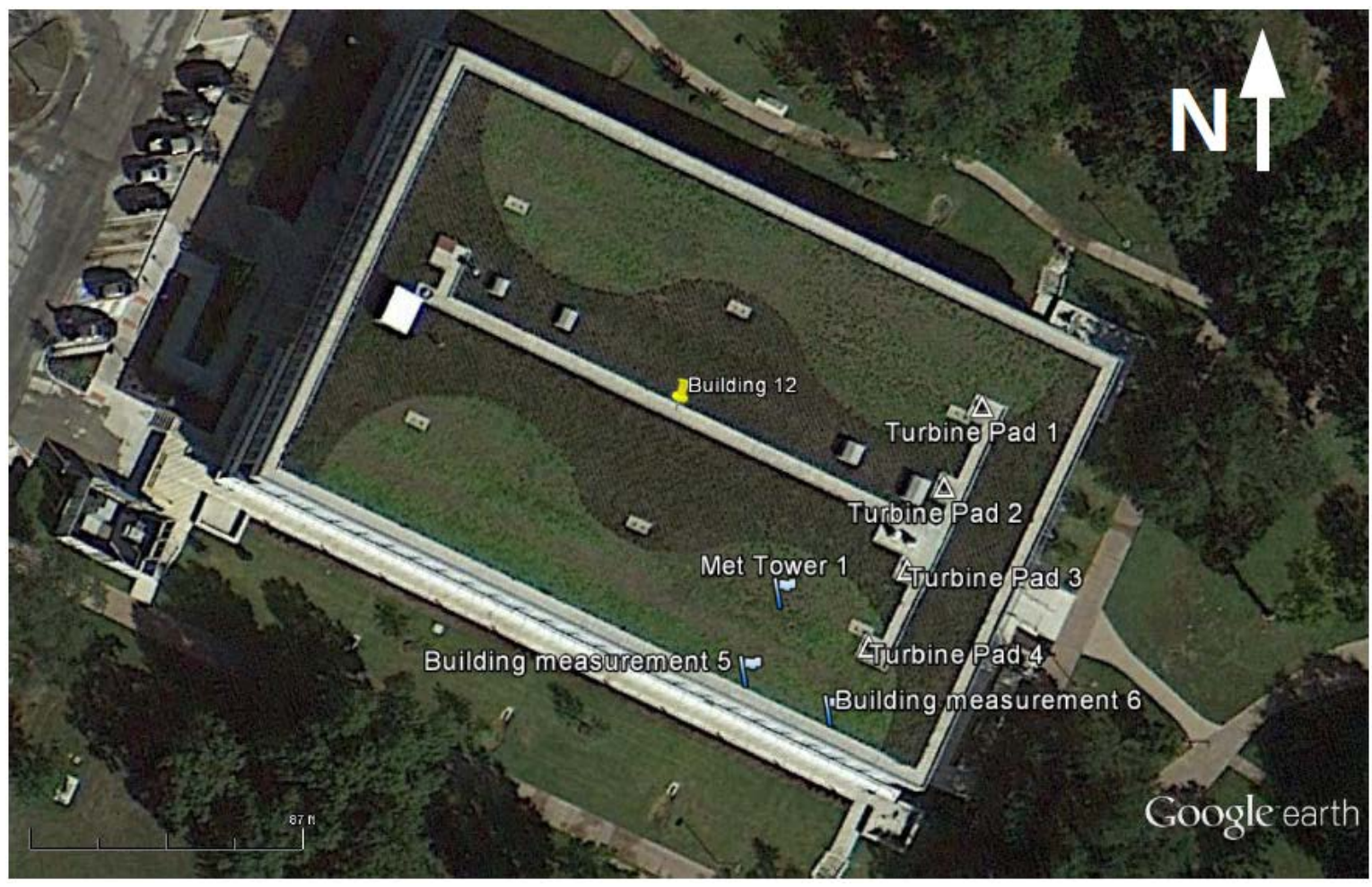

Figure 14. Aerial satellite photo showing the layout of the NASA Building 12 project 


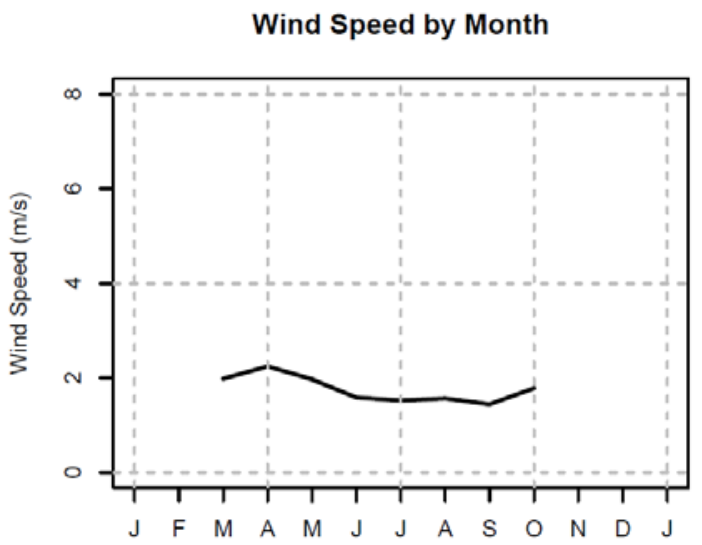

Figure 15. NASA Building 12 monthly average wind speeds
- The resource and technology must match. During Phase 1 of the NASA-NREL/Department of Energy collaboration, the project developers conducted an 8-month onsite resource assessment prior to construction but after committing to the installation. The assessment included anemometer measurements at sites that have since become turbine locations (Figure 15). Although the assessment revealed that the site has a low wind resource $(<2 \mathrm{~m} / \mathrm{s})$, the project moved forward with Phase 2, which included the installation of four Eddy GT turbines.

Since installation, the project has been hindered by low production. This can be attributed to the resource not matching the required cut-in speed for the

technology to begin generating power $(\sim 3.5 \mathrm{~m} / \mathrm{s})$. Additionally, the turbines have not produced as much power as even the low winds would predict using a simple convolution of the wind speed frequency distribution with the wind turbine power curve. It is currently believed that the inverters represent the discrepancy in the expected power from wind speed measurements versus actual turbine power measurements. The inverters require a sustained minimum wind speed in order to function. This minimum duration is often not achieved, and the energy produced from the turbine is converted into heat energy for system protection. This setup is sometimes known as a dump load. The low wind speeds combined with the inverter setup mean that the NASA Building 12 turbines are performing well below their anticipated generation and even the potential as measured with wind speed. This demonstrates the critical link not only between anticipated generation and onsite measurements but also the need to account for losses as part of the energy estimation process.

Figure 16 demonstrates the marked difference between expected power and actual power. The figure represents the measured wind speed as WS (mps), the predicted energy as UGE PWR, and the actual measured turbine energy as Watts 1-4. UGE PWR is created by convolving the measured wind speed with the manufacturer's turbine power curve. The difference between the UGE PWR and Watts1-4 is dramatic, with the turbines only producing power in rare higher-wind events. The actual energy production values for March 2015 are shown in Table 4. The last column also demonstrates how long in hours a typical 60-watt light bulb could be powered with the energy generated from the turbines over the course of the month. 


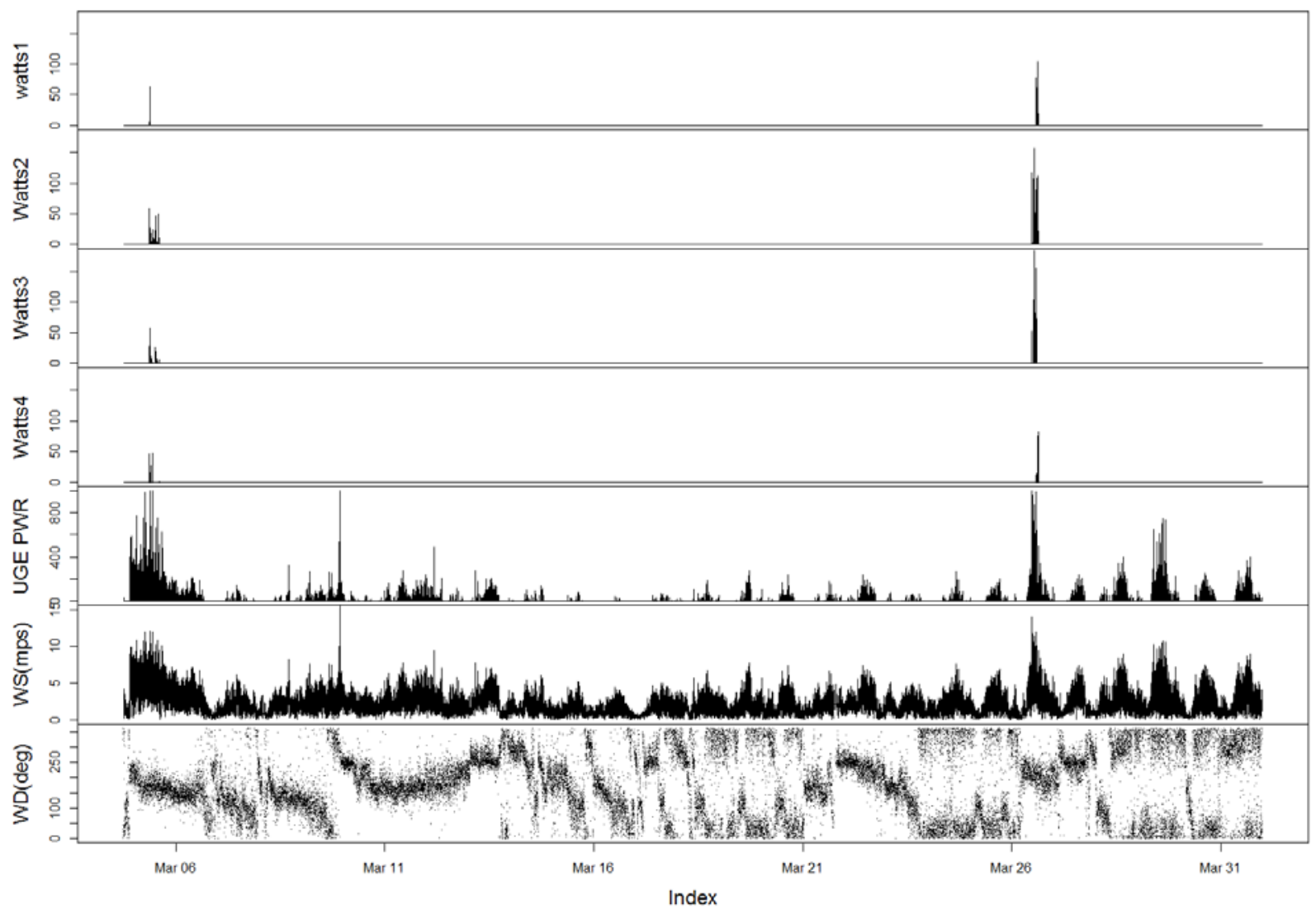

Figure 16. Monitoring data from the NASA Building 12 for March 2015 including wind direction (WD), wind speed (WS), expected power (UGE PWR), and actual power in watts for the four installed turbines

Table 4. NASA Building 12 Predicted vs. Actual Energy (March 2015)

\begin{tabular}{cccc}
\hline Turbine & Energy (Wh) & Capacity Factor (\%) & $\begin{array}{c}\text { 60-W Light Bulb Duration } \\
\text { (Hours) }\end{array}$ \\
\hline 1 & 16.54 & $0.0022 \%$ & 0.28 \\
\hline 2 & 59.10 & $0.0079 \%$ & 0.99 \\
3 & 33.12 & $0.0045 \%$ & 0.55 \\
4 & 8.16 & $0.0011 \%$ & 0.14 \\
\hline UGE PWR & 7810.0 & $1.05 \%$ & 130.17 \\
\hline
\end{tabular}

*predicted energy from concurrent wind speed measurements and UGE power curve

The measurement program also yields some unique data with which to evaluate BEWT projects. The following image is an analysis of the TI for the four pad-mounted instruments during the preconstruction measurement campaign. This is plotted against the IEC 61400-2 turbulence curve, which represents the class A turbulence level. The plot shows a large cluster of TI values below the recommended IEC design criteria. However, upon closer inspection, one can see that all turbine locations exhibit instances of extremely high TI values, which would lead to both power and reliability concerns. 

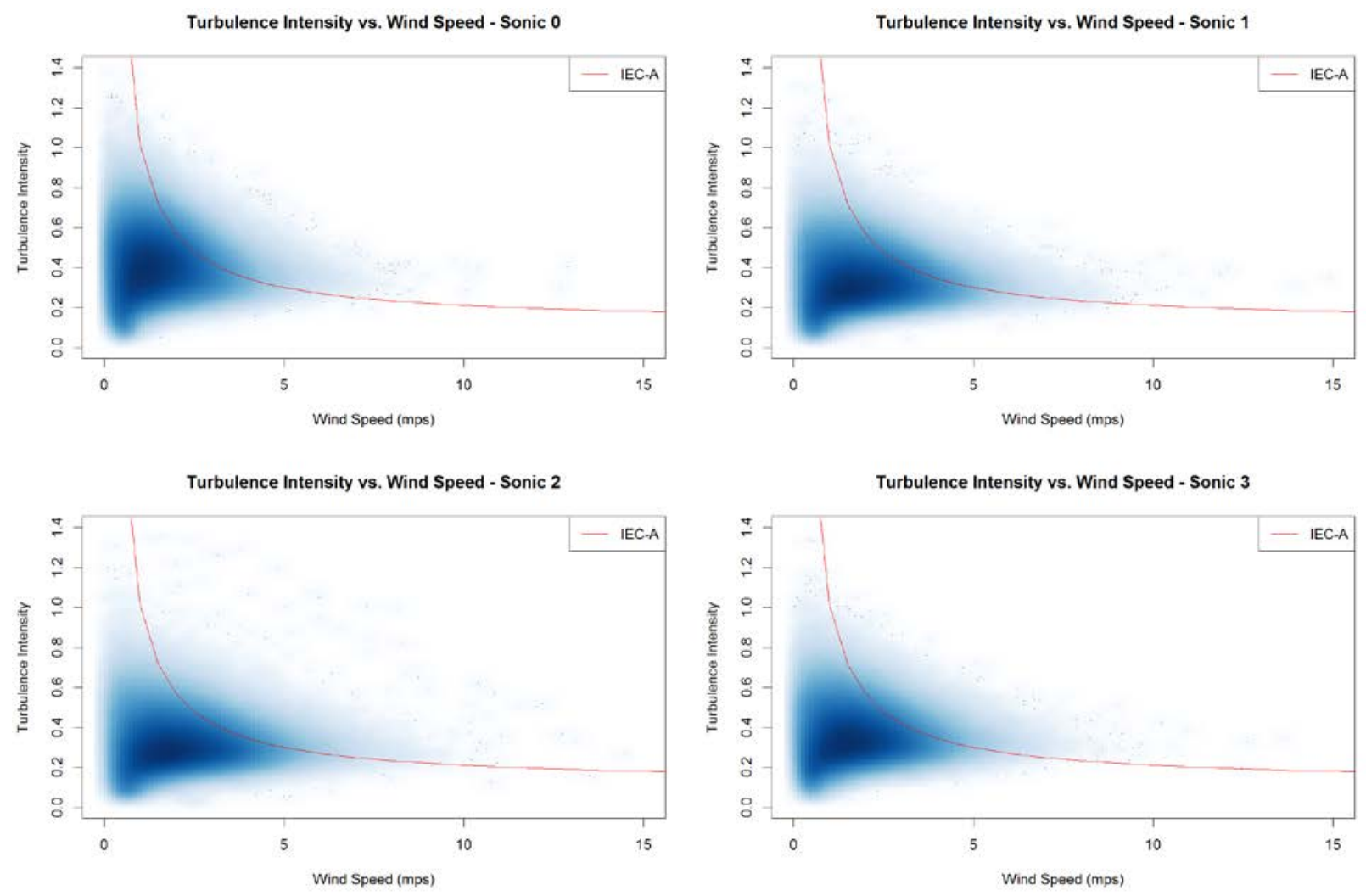

Figure 17. NASA Building 12 TI vs. wind speed

\section{Additional Notes}

According to project developers, turbine selection was influenced by two factors: wildlife impacts and wind speed requirements. In terms of wildlife, NASA's Environmental Office preferred that the turbine be a vertical-axis machine as opposed to a horizontal-axis machine in order to reduce potential avian impacts. The wind speed requirements impacted turbine selection by limiting tower height of the installation, thus limiting the turbine models that could be utilized in the project.

Project developers intended to install Tangarie GALE 5-kW vertical-axis wind turbines, but the manufacturer went out of business after the order was placed. Since the wind turbine installation was part of a larger renovation of Building 12, the subsequent delay caused NASA officials to reduce the scope of work for the general contractors that were hired to construct the entire renovation project, including the wind turbine installation. Once the new turbine model was selected, NASA onsite maintenance contractors completed the installation.

Johnson Space Center has a previous wind turbine installation at its Child Care Center. The project is located in an area with fewer surrounding structures that could impact the wind resource. The Skystream turbines utilized for this project have been generating in line with production estimates. 